\title{
Nonpharmacological interventions to reduce respiratory viral transmission: an evidence-based review with recommendations*
}

\author{
Erick Yuen', Jacob Fried', Craig Salvador', David A. Gudis², Rodney J. \\ Schlosser', Shaun A. Nguyen', Emily A. Brennan', Nicholas R. Rowan ${ }^{3}$ \\ Rhinology 59: 2, 114 - 132, 2021 \\ https://doi.org/10.4193/Rhin20.563 \\ 'Medical University of South Carolina, Department of Otolaryngology-Head and Neck Surgery, Charleston, SC, USA \\ *Received for publication: \\ October 30, 2020 \\ ${ }^{2}$ Columbia University Irving Medical Centre, Department of Otolaryngology-Head and Neck Surgery, New York, NY, USA \\ Accepted: December 15, 2020
}

\begin{abstract}
Background: Viral respiratory infections are a leading cause of worldwide mortality and exert the potential to cause global socioeconomic crises. However, inexpensive, efficacious, and rapidly deployable strategies to reduce viral transmission are increasingly important in the setting of an ongoing pandemic, though not entirely understood. This article provides a comprehensive review of commonly employed nonpharmacological interventions to interrupt viral spread and provides evidence-based recommendations for their use.
\end{abstract}

Methodology: A systematic review of three databases was performed. Studies with defined endpoints of subjects receiving one of five interventions (nasal washing, gargling, personal protective equipment (PPE), social distancing, and hand hygiene) were included. An evidence-based review of the highest level of evidence, with recommendations, was created in accordance with a previously described, rigorous, iterative process.

Results: Fifty-four primary studies were included. The most commonly studied intervention was hand hygiene, followed by PPE, gargling, saline nasal washing, and social distancing.

Conclusions: Mask use and hand hygiene are strong recommendations for prevention of viral transmission. Donning gloves, gowns, and eye protection are a recommendation in healthcare settings. Saline nasal washing and gargling are options in selected populations. Although an aggregate level of evidence is not provided, the authors recommend social distancing.

Key words: COVID-19, evidence-based medicine, viral infection, prophylaxis

\section{Introduction}

Although often self-limited, viral respiratory tract infections (VRTI) are associated with an enormous burden of disease. The total economic impact of non-influenza-related VRTIs approaches $\$ 40$ billion in direct and indirect costs annually ${ }^{(1)}$. As highlighted by the current coronavirus disease of 2019 (COVID-19) pandemic, respiratory viruses are capable of causing vast morbidity and mortality in addition to social and economic crises. Such disease outbreaks over the past two decades have included Severe Acute Respiratory Syndrome Coronavirus (SARS-CoV) in 2003, Middle Eastern Respiratory Syndrome Coronavirus (MERS-CoV) in 2012, and most recently, Severe Acute
Respiratory Syndrome Coronavirus 2 (SARS-CoV-2).

Nonpharmacological interventions (NPI), which are often inexpensive and simple to implement for a wide-scale population, have enormous value in curtailing transmission in both healthcare and community settings. These methods can be instituted rapidly and demonstrate efficacy independent of the specific infectious pathogen, including novel viruses for which more targeted therapy may not be available ${ }^{(2)}$. Given the anatomic tropism to the sinonasal cavity and nasopharynx of these viruses, rhinologists are frequently positioned on the front-lines of viral outbreaks, and are potentially at increased risk of both infection and transmission based on their unique clinical exper- 
tise. Although the effectiveness of various NPIs to reduce viral transmission have been previously reported ${ }^{(2,3)}$, they have not to our knowledge been examined using an iterative evidencebased process.

The objective of this study is to thoroughly assess the current literature on the efficacy of five principal NPIs to reduce upper VRTI transmission using a structured and systematic review process, and provide evidence-based recommendations where possible: nasal washing, gargling, personal protective equipment (PPE), social distancing, and hand hygiene. Though recommendations are provided, this review is intended not to replace clinical judgment, but rather to inform the medical community, in particular rhinologists, about the evidence for behavioural strategies that may be employed to combat outbreaks caused by respiratory viruses and to provide foundation for future research.

\section{Materials and methods}

\section{Study design}

An evidence-based review with recommendations was prepared using an online iterative process, following the methodology described by Rudmik and Smith ${ }^{(4)}$. The Clinical Practice Guideline Manual(5), Conference on Guideline Standardization (COGS) ${ }^{(6)}$, and the Appraisal of Guidelines and Research Evaluation $(A G R E E)^{(7)}$ instrument recommendations were followed to improve quality, transparency, and reporting of results in this review. This study was conducted according to Preferred Reporting Items for Systematic Reviews and Meta-Analyses (PRISMA) guidelines ${ }^{(8)}$.

\section{Literature search strategy}

To identify studies for inclusion, a research informationist (E.A.B.) developed detailed search strategies in the following three databases: PubMed (U.S. National Library of Medicine, National Institutes of Health), Scopus (Elsevier), and CINAHL (EBSCOhost). Databases were queried from date of inception through July 7, 2020, and English language filters were applied. The search strategies used a combination of subject headings (e.g., MeSH in PubMed) and keywords for all relevant concepts. The PubMed search strategy was modified for the other two databases, replacing MeSH terms with appropriate subject headings, when available, and maintaining similar keywords. The search strategies for each database are detailed in Appendix 1. In an effort to identify and provide the highest level of evidence, database searches were limited to systematic review and meta-analyses when available. For comprehensive review, and to identify additional articles, the reference lists of both systematic reviews and primary articles were hand-searched. References were exported into the Covidence review management software (Veritas Health Innovation Ltd, Melbourne, Australia) for study selection.

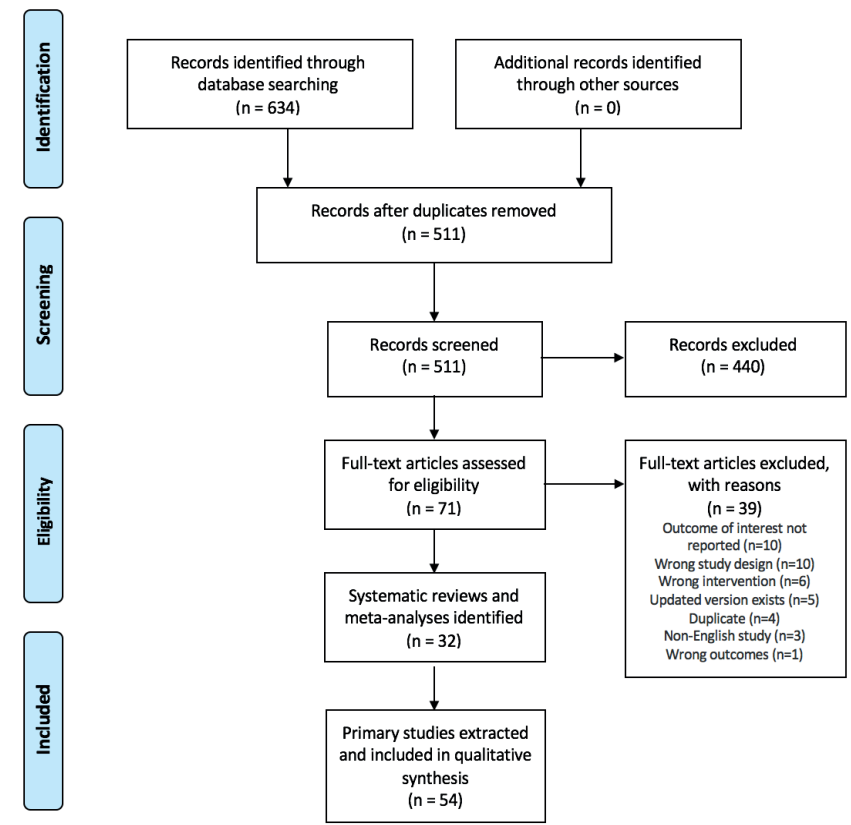

Figure 1. Preferred reporting items for systematic reviews and metaanalyses diagram.

Inclusion and exclusion criteria

Studies investigating the effectiveness of the five aforementioned NPIs in preventing upper VRTI transmission were included. Data from primary studies was subsequently extracted and assessed for study eligibility. Original articles with clearly defined primary clinical endpoint(s) were included. Exclusion criteria included non-English language, non-human studies, duplicates, and case reports, case series, editorials, and practice guidelines. Studies that specified a clinical endpoint involving lower respiratory tract infections and those that solely examined the effect of multicomponent interventions, such as the concurrent use of face masks and hand hygiene, were excluded. Furthermore, studies that evaluated the role of these interventions in treating VRTIs and those in which data for outcomes of interest could not be extracted were not considered.

\section{Data extraction and collection}

After duplicates were removed, all abstracts and records were independently reviewed by two authors (E.Y. and C.S.). Following abstract review, ineligible articles were excluded while the remaining studies underwent full-text review. Any disagreements in inclusion were resolved by consensus, then outcomes data were independently extracted from each eligible individual study.

\section{Development of recommendations}

Summary tables were developed for the included articles. Aggregate grade of evidence (A to D), benefit-harm assessment, and value judgments were developed for each NPI studied. An 
Table 1. Quality rating according to Oxford centre for evidence-based medicine.

1 Properly powered and conducted randomized clinical trial; systematic review with meta-analysis

2 Well-designed controlled trial without randomization; prospective comparative cohort trial

3 Case-control studies; retrospective cohort study

4 Case series with or without intervention; cross-sectional study

5 Opinion of respected authorities; case reports

aggregate grade of evidence was not provided for any intervention investigated by only a single study. Studies were graded for level of evidence using the 2011 Oxford Centre for EvidenceBased Medicine Criteria (Table 1) ${ }^{(9)}$. Recommendations based on the American Academy of Pediatrics guidelines ${ }^{(10)}$ were made if sufficient evidence was available (Table 2). The initial manuscript was prepared by two authors (E.Y. and J.F.). Additional authors were then asked to critically evaluate the literature and provide recommendations (D.A.G., N.R.R., and R.J.S.) as per the protocol for the online iterative process ${ }^{(4)}$. Any disagreements amongst the authors were debated electronically until a consensus was reached.

\section{Results}

\section{Search characteristics}

The literature search yielded a total of 511 unique systematic reviews after de-duplication. A diagram outlining the summary of the search process is shown in Figure 1. A total of 32 systematic reviews and meta-analyses ${ }^{(2,3,11-40)}$ met inclusion. Fifty-four individual studies were subsequently extracted and included in the final analysis.

The highest level of evidence was considered for each NPI studied. Case-control studies for saline nasal washing ${ }^{(41,42)}$ and PPE (gowns, gloves, and eye protection) $)^{(41-46)}$, and randomized controlled trials (RCTs) for gargling ${ }^{(47-50)}$, social distancing ${ }^{(51)}$, mask $u^{(52-65)}$, and hand hygiene ${ }^{(66-94)}$ were identified through this review. The results of the individual studies extracted from these reviews are summarized in Tables 3-10 and are discussed in the following sections. A summary of evidence and recommendations is provided in cases where sufficient data exists to support one. Regarding the quality of individual studies, 48 studies were level 2 while six studies were level 4.

\section{Saline nasal washing}

The literature search identified two case-control studies (level 4 evidence) evaluating the role of saline nasal washing in preventing SARS infection in healthcare workers (Table 3). Both studies retrospectively assessed the nasal washing habits of hospital personnel caring for SARS patients via questionnaires. Although Chen et al. ${ }^{(41)}$ found that the frequency of nasal cavity washing was not significantly associated with reduced odds of infection, Liu et al. ${ }^{(42)}$ reported that this strategy conferred a protective effect. The two studies are at high risk of bias. First, neither study tested a defined hypothesis; rather, both analysed a myriad of variables to identify associations in living healthcare workers. Second, there was no attempt at matching cases with controls, and whether interviewers were blinded to the subjects' respective study groups was not addressed. A mortality rate of up to $20 \%$ of infected healthcare workers in the first weeks of the SARS epidemic ${ }^{(42)}$ poses a potentially significant risk for selection bias. Finally, as with all retrospective surveys, recall bias is a concern. Consideration of these shortcomings was acknowledged during interpretation of the included data.

\section{Summary: Saline nasal washing}

1. Aggregate grade of evidence: $C$

2. Benefit: Reduced VRTI transmission

3. Harm: Physical discomfort, time-cost of performing washing

4. Cost: Low (cost of nasal saline bottle, and saline, in addition to short preparation and execution time)

5. Benefits-harm assessment: Preponderance of benefit over harm

6. Value judgments: With minimal potential harm and low cost, there may be moderate value to augment an innate

Table 1. Quality rating according to Oxford centre for evidence-based medicine.

\begin{tabular}{|llll}
\hline Grade & Research quality & Preponderance of benefit over harm & Balance of benefit and harm \\
\hline A & Well-designed RCTs & Strong recommendation & Option \\
\hline B & $\begin{array}{l}\text { RCTs with minor limitations; overwhelming consis- } \\
\text { tent evidence from observational studies }\end{array}$ & Strong recommendation/recommendation & Option \\
\hline C & $\begin{array}{l}\text { Observational studies (case control and cohort } \\
\text { design) }\end{array}$ & Recommendation & Option \\
\hline D & $\begin{array}{l}\text { Expert opinion; case report; reasoning from first } \\
\text { principles }\end{array}$ & Option & No recommendation \\
\hline
\end{tabular}

$\mathrm{RCT}$ : randomized controlled trials. 
Table 3. Summary of nasal washing studies.

\begin{tabular}{|c|c|c|c|c|c|c|c|c|c|}
\hline Study & Year & $\begin{array}{l}\text { Study } \\
\text { Design }\end{array}$ & LOE & Definition of VRTI & $\begin{array}{l}\text { No. of } \\
\text { Subjects }\end{array}$ & $\begin{array}{l}\text { Study } \\
\text { Group(s) }\end{array}$ & Study Protocol & $\begin{array}{l}\text { Primary } \\
\text { endpoint(s) }\end{array}$ & Conclusion \\
\hline Chen et al. & 2009 & $\begin{array}{l}\text { Case-con- } \\
\text { trol study }\end{array}$ & 4 & $\begin{array}{l}\text { 1. Probable SARS } \\
\text { cases }^{\text {a }} \\
\text { 2. SARS IgG posi- } \\
\text { tivity }\end{array}$ & $748 \mathrm{HCWs}$ & $\begin{array}{l}\text { 1. SARS IgG } \\
\text { positive } \\
\text { 2. SARS IgG } \\
\text { negative }\end{array}$ & $\begin{array}{l}\text { Questionnaire: } \\
\text { Frequency of } \\
\text { nasal cavity } \\
\text { washing after } \\
\text { caring for SARS } \\
\text { patients? }\end{array}$ & $\begin{array}{l}\text { 1. SARS } \\
\text { infection } \\
\text { rate }\end{array}$ & $\begin{array}{l}\text { Odds of infec- } \\
\text { tion not redu- } \\
\text { ced with nasal } \\
\text { cavity washing } \\
\text { (OR } 3.21 \text { [0.98- } \\
10.53] \text { ). }\end{array}$ \\
\hline Liu et al. & 2009 & $\begin{array}{l}\text { Case-con- } \\
\text { trol study }\end{array}$ & 4 & $\begin{array}{l}\text { 1. Probable SARS } \\
\text { cases }^{b} \\
\text { 2. SARS IgG posi- } \\
\text { tivity }\end{array}$ & 477 HCWs & $\begin{array}{l}\text { 1. SARS IgG } \\
\text { positive } \\
\text { 2. SARS IgG } \\
\text { negative }\end{array}$ & $\begin{array}{l}\text { Questionnaire: } \\
\text { Nasopharyngeal } \\
\text { rinse after atten- } \\
\text { ding to patients } \\
\text { performed? }\end{array}$ & $\begin{array}{l}\text { 1. SARS } \\
\text { infection } \\
\text { rate }\end{array}$ & $\begin{array}{l}2.4 x \text { higher } \\
\text { likelihood of in- } \\
\text { fection without } \\
\text { nose washing. }\end{array}$ \\
\hline
\end{tabular}

HCW: healthcare workers, LOE: level of evidence, OR: odds ratio, SARS: severe acute respiratory syndrome, VRTI: viral respiratory tract infection.

a Defined using criteria provided by the China Health Ministry: Travel to a SARS epidemic area in the 2 weeks before the onset of symptoms or close contact with a probable SARS patient, fever of $\geq 38^{\circ} \mathrm{C}$, chest $\mathrm{x}$-ray abnormalities, normal or decreased leukocyte count, and no response to treatment by antimicrobial drugs. ${ }^{\text {b }}$ Defined by World Health Organization's criteria: Documented fever $\left(>38^{\circ} \mathrm{C}\right)$, presence of cough or breathing difficulty, AND a significant history of exposure to a SARS patient not more than 10 days prior to onset of symptoms OR a suspect case with radiographic evidence of infiltrates consistent with pneumonia or respiratory distress syndrome on chest x-ray.

Table 4. Summary of gargling studies.

\begin{tabular}{|c|c|c|c|c|c|c|c|c|c|}
\hline Study & Year & $\begin{array}{l}\text { Study } \\
\text { Design }\end{array}$ & LOE & Definition of VRTI & $\begin{array}{l}\text { No. of } \\
\text { Subjects }\end{array}$ & $\begin{array}{l}\text { Study } \\
\text { Group(s) }\end{array}$ & Study Protocol & $\begin{array}{l}\text { Primary } \\
\text { endpoint(s) }\end{array}$ & Conclusion \\
\hline $\begin{array}{l}\text { Sato- } \\
\text { mura et } \\
\text { al. }\end{array}$ & 2005 & $\begin{array}{l}\text { Non- } \\
\text { blinded } \\
\text { RCT }\end{array}$ & 3 & $\begin{array}{l}\text { 1. Nasal/pharyngeal } \\
\text { symptoms AND } \\
\text { 2. Increased symp- } \\
\text { tom severity by } 2 \\
\text { grades }{ }^{\text {a }} \text { AND } \\
\text { 3. Symptom worse- } \\
\text { ning of } \geq 1 \text { increment } \\
\text { for } \geq 3 \text { days }\end{array}$ & $\begin{array}{l}387 \text { healthy } \\
\text { volunteers }\end{array}$ & $\begin{array}{l}\text { 1. Tap water } \\
\text { gargling }^{\text {b }} \\
\text { 2. PVP-I } \\
\text { gargling } \\
\text { 3. Control } \\
\text { (maintain } \\
\text { previous } \\
\text { gargling } \\
\text { habits) }\end{array}$ & $\begin{array}{l}\text { Daily frequency } \\
\text { of gargling and } \\
\text { URI complaints } \\
\text { recorded. }\end{array}$ & $\begin{array}{l}\text { 1. URI inci- } \\
\text { dence rate }\end{array}$ & $\begin{array}{l}\text { Only tap water garg- } \\
\text { ling associated with } \\
\text { URI prevention (IRR } \\
0.64 \text { [0.41-0.99]). }\end{array}$ \\
\hline $\begin{array}{l}\text { Toyoi- } \\
\text { zumi et } \\
\text { al. }\end{array}$ & 2013 & $\mathrm{RCT}$ & 2 & $\begin{array}{l}\text { 1. Positive assay } \\
\text { for influenza virus } \\
\text { antigen } O R \\
2 \text {. Fever }\left(37.8^{\circ} \mathrm{C}\right) \text { and } \\
2 \text { of the following: } \\
\text { cough, sore throat, } \\
\text { headache, and } \\
\text { myalgia }\end{array}$ & $\begin{array}{l}308 \text { high } \\
\text { school } \\
\text { students }\end{array}$ & $\begin{array}{l}\text { 1. Green tea } \\
\text { gargling } \\
\text { 2. Tap water } \\
\text { gargling }\end{array}$ & $\begin{array}{l}\text { Symptoms } \\
\text { reported to } \\
\text { physician or } \\
\text { school nurse. }\end{array}$ & $\begin{array}{l}\text { 1. Incidence } \\
\text { of influenza }\end{array}$ & $\begin{array}{l}\text { No significant diffe- } \\
\text { rence between green } \\
\text { tea }(7.1 \%) \text { and water } \\
(7.9 \%) \text { gargling. }\end{array}$ \\
\hline $\begin{array}{l}\text { Ide et } \\
\text { al. }\end{array}$ & 2014 & $\begin{array}{l}\text { Non- } \\
\text { blinded } \\
\text { RCT }\end{array}$ & 3 & $\begin{array}{l}\text { 1. Lab-confirmed } \\
\text { influenza }\end{array}$ & $\begin{array}{l}757 \text { high } \\
\text { school } \\
\text { students }\end{array}$ & $\begin{array}{l}\text { 1. Green tea } \\
\text { gargling } \\
\text { 2. Tap water } \\
\text { gargling }\end{array}$ & $\begin{array}{l}\text { Questionnaire: } \\
\text { Occurrence of } \\
\text { influenza infec- } \\
\text { tion? }\end{array}$ & $\begin{array}{l}\text { 1. Incidence } \\
\text { of lab- } \\
\text { confirmed } \\
\text { influenza }\end{array}$ & $\begin{array}{l}\text { No significant diffe- } \\
\text { rence between green } \\
\text { tea }(4.9 \%) \text { and water } \\
(6.9 \%) \text { groups. }\end{array}$ \\
\hline $\begin{array}{l}\text { Yamada } \\
\text { et al. }\end{array}$ & 2007 & $\begin{array}{l}\text { Double- } \\
\text { blinded } \\
\text { RCT }\end{array}$ & 2 & $\begin{array}{l}\text { 1. Positive rapid } \\
\text { assay for influenza } \\
\text { virus antigens. Assay } \\
\text { performed if subject } \\
\text { had ILI } \\
\text { 2. URI }\end{array}$ & $\begin{array}{l}404 \text { healthy } \\
\text { volunteers }\end{array}$ & $\begin{array}{l}\text { 1. Tea cate- } \\
\text { chin extract } \\
\text { garglingf } \\
\text { 2. Without } \\
\text { tea catechin } \\
\text { extract } \\
\text { gargling }\end{array}$ & $\begin{array}{l}\text { Presence/seve- } \\
\text { rity of cold-rela- } \\
\text { ted symptoms } \\
\text { recorded. }\end{array}$ & $\begin{array}{l}\text { 1. Incidence } \\
\text { of lab- } \\
\text { confirmed } \\
\text { influenza } \\
2 \text {. Incidence } \\
\text { of URI }\end{array}$ & $\begin{array}{l}\text { No significant dif- } \\
\text { ference between } \\
\text { catechin (1\%) and } \\
\text { control }(2 \%) \text { groups. }\end{array}$ \\
\hline
\end{tabular}

ILI: influenza-like illness, IRR: incidence rate ratio, LOE: level of evidence, PVP-I: povidone-iodine, RCT: randomized controlled trial, URI: upper respira-

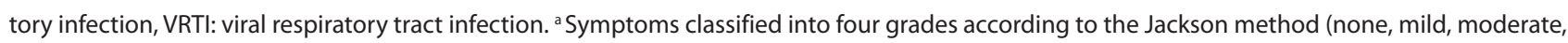
and severe). ${ }^{b}$ Gargling regimen: $20 \mathrm{~mL}$ for 15 seconds $3 x$ consecutively for at least $3 x$ per day. ${ }^{c}$ Gargled $3 x$ daily for 90 days. ${ }^{d}$ Temperature of $\geq 37.8^{\circ} \mathrm{C}$ and a recent or aggravated cough plus suggestive symptoms. ${ }^{e}$ Presence of cold-related symptoms but not ILI. ${ }^{f} \mathrm{Gargled}$ for 15 seconds, 3 times consecutively, 3 times daily for 90 days. 
Table 5. Summary of wearing mask studies.

\begin{tabular}{|c|c|c|c|c|c|c|c|c|c|}
\hline Study & Year & $\begin{array}{l}\text { Study } \\
\text { Design }\end{array}$ & LOE & Definition of VRTI & $\begin{array}{l}\text { No. of Sub- } \\
\text { jects }\end{array}$ & $\begin{array}{l}\text { Study } \\
\text { Group(s) }\end{array}$ & Study Protocol & $\begin{array}{l}\text { Primary } \\
\text { endpoint(s) }\end{array}$ & Conclusion \\
\hline $\begin{array}{l}\text { Macln- } \\
\text { tyre et al. } \\
(58)\end{array}$ & 2009 & $\begin{array}{l}\text { Cluster } \\
\mathrm{RCT}\end{array}$ & 2 & $\begin{array}{l}\text { 1. ILI }{ }^{\mathrm{a}} \text { or } \\
\text { 2. Symptom + lab } \\
\text { confirmation of } \\
\text { viral infection }\end{array}$ & $\begin{array}{l}290 \text { adults } \\
\text { from } 145 \\
\text { families }\end{array}$ & $\begin{array}{l}\text { 1. Surgical } \\
\text { mask } \\
\text { 2. P2 (N95) } \\
\text { mask } \\
\text { 3. No mask }\end{array}$ & $\begin{array}{l}\text { Masks worn } \\
\text { when in the } \\
\text { same room as } \\
\text { index child. } \\
\text { Daily symptom } \\
\text { assessment. }\end{array}$ & $\begin{array}{l}\text { 1. ILI HR } \\
\text { 2. Lab-con- } \\
\text { firmed viral } \\
\text { infection }^{\text {b }}\end{array}$ & $\begin{array}{l}75 \% \text { less likely to deve- } \\
\text { lop ILI with mask use. } \\
\text { Unable to determine } \\
\text { difference between } \\
\text { masks. }\end{array}$ \\
\hline $\begin{array}{l}\text { Maclnty- } \\
\text { re et al. }\end{array}$ & 2016 & $\begin{array}{l}\text { Cluster } \\
\mathrm{RCT}\end{array}$ & 2 & $\begin{array}{l}\text { 1. } \mathrm{CRI}^{\mathrm{c}} \\
\text { 2. } \mathrm{ILI}^{\mathrm{d}} \\
\text { 3. Lab-confirmed } \\
\text { viral respiratory } \\
\text { infectione }\end{array}$ & $\begin{array}{l}245 \text { index } \\
\text { cases in } 597 \\
\text { households }\end{array}$ & $\begin{array}{l}\text { 1. Surgical } \\
\text { mask (for } \\
\text { index cases } \\
\text { only) } \\
\text { 2. No mask }\end{array}$ & $\begin{array}{l}\text { Symptomatic } \\
\text { individuals } \\
\text { meeting 'CRI' } \\
\text { definition were } \\
\text { tested for } \\
\text { VRTI. }\end{array}$ & $\begin{array}{l}\text { In contacts, } \\
\text { RR of: } \\
\text { 1. CRI } \\
\text { 2. ILI } \\
\text { 3. Lab-con- } \\
\text { firmed viral } \\
\text { respiratory } \\
\text { infection }\end{array}$ & $\begin{array}{l}\text { No significant difference } \\
\text { in RR of: } \\
\text { CRI: } 0.61[0.18-2.13] \\
\text { ILI: } 0.32[0.03-3.13] \\
\text { Lab: } 0.97[0.06-15.54]\end{array}$ \\
\hline $\begin{array}{l}\text { Cowling } \\
\text { et al. }\end{array}$ & 2008 & $\begin{array}{l}\text { Cluster } \\
\mathrm{RCT}\end{array}$ & 2 & $\begin{array}{l}\text { 1. Positive viral } \\
\text { culture or PCR for } \\
\text { influenza } \\
\text { 2. Clinical defini- } \\
\text { tions }\end{array}$ & $\begin{array}{l}198 \text { index } \\
\text { subjects in } \\
128 \text { house- } \\
\text { holds }\end{array}$ & $\begin{array}{l}\text { 1. Surgical } \\
\text { mask } \\
\text { 2. Hand } \\
\text { hygiene } \\
\text { 3. Control } \\
\text { (education) }\end{array}$ & $\begin{array}{l}\text { Symptom diary } \\
\text { completed by } \\
\text { contacts. Nasal/ } \\
\text { throat swabs col- } \\
\text { lected. }\end{array}$ & $\begin{array}{l}\text { 1. SAR } \\
\text { among } \\
\text { household } \\
\text { contacts }\end{array}$ & $\begin{array}{l}\text { SAR for mask ( } 7 \%) \text {, } \\
\text { hand hygiene }(6 \%) \text {, and } \\
\text { control }(6 \%) \text { groups did } \\
\text { not differ. }\end{array}$ \\
\hline $\begin{array}{l}\text { Aiello } \\
\text { et al. }\end{array}$ & 2010 & $\begin{array}{l}\text { Cluster } \\
\text { RCT }\end{array}$ & 2 & $\begin{array}{l}\text { 1. Cough and } \geq 1 \\
\text { constitutional } \\
\text { symptom }\end{array}$ & $\begin{array}{l}1297 \\
\text { students in } \\
7 \text { resident } \\
\text { halls }\end{array}$ & $\begin{array}{l}\text { 1. Face } \\
\text { masks only } \\
2 . \text { No inter- } \\
\text { vention }\end{array}$ & $\begin{array}{l}\text { Respiratory ill- } \\
\text { ness symptoms } \\
\text { were documen- } \\
\text { ted. }\end{array}$ & $\begin{array}{l}\text { 1. ILI inci- } \\
\text { dence }\end{array}$ & $\begin{array}{l}\text { No significant incidence } \\
\text { reduction during total } \\
\text { study period (IRR } 0.90 \\
{[0.77-1.05] \text { ). }}\end{array}$ \\
\hline $\begin{array}{l}\text { Aiello } \\
\text { et al. }\end{array}$ & 2012 & $\begin{array}{l}\text { Cluster } \\
\text { RCT }\end{array}$ & 2 & $\begin{array}{l}\text { 1. ILI }{ }^{\mathrm{f}} \\
\text { 2. Lab-confirmed } \\
\text { influenza A/B }\end{array}$ & $\begin{array}{l}1,178 \text { young } \\
\text { adults in } 37 \\
\text { residence } \\
\text { houses }\end{array}$ & $\begin{array}{l}\text { 1. Facemask } \\
\text { only } \\
\text { 2. Control }\end{array}$ & $\begin{array}{l}\text { Symptoms } \\
\text { surveyed. Throat } \\
\text { swabs obtained } \\
\text { for symptomatic } \\
\text { patients. }\end{array}$ & $\begin{array}{l}\text { 1. ILI inci- } \\
\text { dence } \\
\text { 2. Lab- } \\
\text { confirmed } \\
\text { influenza }\end{array}$ & $\begin{array}{l}\text { No significant incidence } \\
\text { reduction as measu- } \\
\text { red by ILI (IRR } 1.10 \\
\text { [0.88-1.38]) and lab- } \\
\text { confirmation (IRR } 0.92 \\
\text { [0.59-1.42]). }\end{array}$ \\
\hline $\begin{array}{l}\text { Ba- } \\
\text { rasheed } \\
\text { et al. }\end{array}$ & 2014 & $\begin{array}{l}\text { Non- } \\
\text { blinded } \\
\text { cluster } \\
\text { RCT }\end{array}$ & 2 & $\begin{array}{l}\text { 1. Lab-confirmed } \\
\text { influenza } A / B \text { and } \\
\text { other respiratory } \\
\text { viruses }\end{array}$ & $\begin{array}{l}164 \text { Hajj } \\
\text { pilgrims }\end{array}$ & $\begin{array}{l}\text { 1. Surgical } \\
\text { masks } \\
\text { 2. No masks }\end{array}$ & $\begin{array}{l}\text { Symptom diary. } \\
\text { Specimens were } \\
\text { collected from } \\
\text { those with ILIg }\end{array}$ & $\begin{array}{l}\text { 1. ILI } \\
\text { symptoms } \\
\text { 2. Virology } \\
\text { lab results }\end{array}$ & $\begin{array}{l}\text { Masks protective } \\
\text { against ILI when com- } \\
\text { pared to control ( } 31 \% \text { vs } \\
53 \%, p=0.04) \text {. }\end{array}$ \\
\hline $\begin{array}{l}\text { Suess et } \\
\text { al. }\end{array}$ & 2012 & $\begin{array}{l}\text { Cluster } \\
\text { RCT }\end{array}$ & 2 & $\begin{array}{l}\text { 1. Lab-confirmed } \\
\text { influenza }\end{array}$ & $\begin{array}{l}218 \text { con- } \\
\text { tacts in } 84 \\
\text { households }\end{array}$ & $\begin{array}{l}\text { 1. Surgical } \\
\text { mask } \\
\text { 2. No mask }\end{array}$ & $\begin{array}{l}\text { Assessed } \\
\text { symptoms. } \\
\text { Nasal swabs for } \\
\text { all household } \\
\text { contacts. }\end{array}$ & $\begin{array}{l}\text { 1. Lab- } \\
\text { confirmed } \\
\text { influenza in } \\
\text { household } \\
\text { contact } \\
\text { 2. ILI occur- } \\
\text { rence }\end{array}$ & $\begin{array}{l}\text { Odds of infection did } \\
\text { not differ with mask use, } \\
\text { as measured by lab (OR } \\
0.39 \text { [0.13-1.19]) and ILI } \\
\text { (OR 0.56 [0.18-1.68]). }\end{array}$ \\
\hline $\begin{array}{l}\text { Canini } \\
\text { et al. }\end{array}$ & 2010 & $\begin{array}{l}\text { Cluster } \\
\text { RCT }\end{array}$ & 2 & $\begin{array}{l}\text { 1. Index case: } \\
\text { Positive rapid } \\
\text { influenza A } \\
\text { 2. Contact: ILI }\end{array}$ & $\begin{array}{l}306 \text { con- } \\
\text { tacts in } 105 \\
\text { homes }\end{array}$ & $\begin{array}{l}\text { 1. Surgical } \\
\text { mask (for } \\
\text { index cases } \\
\text { only) } \\
\text { 2. Control }\end{array}$ & $\begin{array}{l}\text { Daily symptom } \\
\text { questionnaire. }\end{array}$ & $\begin{array}{l}\text { 1. ILI inci- } \\
\text { dence }\end{array}$ & $\begin{array}{l}\text { No significant difference } \\
\text { between mask (16.2\%) } \\
\text { and control (15.8\%) } \\
\text { arms. Study prematurely } \\
\text { terminated. }\end{array}$ \\
\hline $\begin{array}{l}\text { Jacobs } \\
\text { et al. }\end{array}$ & 2009 & $\mathrm{RCT}$ & 2 & $\begin{array}{l}\text { 1. Clinical } \\
\text { symptoms }\end{array}$ & $32 \mathrm{HCWs}$ & $\begin{array}{l}\text { 1. Surgical } \\
\text { masks } \\
\text { 2. No surgi- } \\
\text { cal masks }\end{array}$ & $\begin{array}{l}\text { Daily symptom } \\
\text { diary. }\end{array}$ & $\begin{array}{l}\text { 1. URI inci- } \\
\text { dence }\end{array}$ & $\begin{array}{l}\text { No significant difference } \\
\text { between mask (5.9\%) } \\
\text { and control (6.7\%) arms. }\end{array}$ \\
\hline $\begin{array}{l}\text { Radono- } \\
\text { vich et } \\
\text { al. (65) }\end{array}$ & 2019 & $\begin{array}{l}\text { Cluster } \\
\text { RCT }\end{array}$ & 2 & $\begin{array}{l}\text { 1. Lab-confirmed } \\
\text { influenza }\end{array}$ & $\begin{array}{l}4,051 \text { HCWs } \\
\text { in } 7 \text { medical } \\
\text { centres }\end{array}$ & $\begin{array}{l}\text { 1. N95 } \\
\text { respirator } \\
\text { 2. Surgical } \\
\text { mask }\end{array}$ & $\begin{array}{l}\text { Nasal and throat } \\
\text { swabs collected. }\end{array}$ & $\begin{array}{l}\text { 1. Incidence } \\
\text { of lab- } \\
\text { confirmed } \\
\text { influenza }\end{array}$ & $\begin{array}{l}\text { No significant difference } \\
\text { between N95 (8.2\%) vs. } \\
\text { surgical masks (7.2\%). }\end{array}$ \\
\hline $\begin{array}{l}\text { Loeb et } \\
\text { al. (66) }\end{array}$ & 2009 & $\mathrm{RCT}$ & 2 & $\begin{array}{l}\text { 1. Clinical } \\
\text { symptoms }\end{array}$ & 446 nurses & $\begin{array}{l}\text { 1. N95 } \\
\text { respirator } \\
\text { 2. Surgical } \\
\text { mask }\end{array}$ & $\begin{array}{l}\text { Nasal specimens } \\
\text { collected for } \\
\text { newly reported } \\
\text { symptoms. }\end{array}$ & $\begin{array}{l}\text { 1. Incidence } \\
\text { of lab- } \\
\text { confirmed } \\
\text { influenza }\end{array}$ & $\begin{array}{l}\text { Use of surgical mask } \\
\text { compared with N95 } \\
\text { resulted in non-inferior } \\
\text { rates ( } 23.6 \% \text { vs } 22.9 \% \text { ) of } \\
\text { infection. }\end{array}$ \\
\hline
\end{tabular}




\begin{tabular}{|c|c|c|c|c|c|c|c|c|c|}
\hline Study & Year & $\begin{array}{l}\text { Study } \\
\text { Design }\end{array}$ & LOE & Definition of VRTI & $\begin{array}{l}\text { No. of Sub- } \\
\text { jects }\end{array}$ & $\begin{array}{l}\text { Study } \\
\text { Group(s) }\end{array}$ & Study Protocol & $\begin{array}{l}\text { Primary } \\
\text { endpoint(s) }\end{array}$ & Conclusion \\
\hline $\begin{array}{l}\text { Macln- } \\
\text { tyre et al. } \\
(62)\end{array}$ & 2011 & $\begin{array}{l}\text { Cluster } \\
\text { RCT }\end{array}$ & 2 & $\begin{array}{l}\text { 1. } \mathrm{CRI}^{\mathrm{c}} \text { or ILI } \\
\text { 2. Lab-confirmed } \\
\text { viral respiratory } \\
\text { infectione or influ- } \\
\text { enza A/B }\end{array}$ & $\begin{array}{l}1,441 \mathrm{HCWs} \\
\text { in } 15 \text { hospi- } \\
\text { tals }\end{array}$ & $\begin{array}{l}\text { 1. Medical } \\
\text { masks } \\
\text { 2. Fit-tested } \\
\text { N95 } \\
\text { 3. Non-fit- } \\
\text { tested N95 } \\
\text { 4. No mask }\end{array}$ & $\begin{array}{l}\text { Daily contact to } \\
\text { identify incident } \\
\text { cases of respira- } \\
\text { tory infection. }\end{array}$ & $\begin{array}{l}\text { 1. CRI and } \\
\text { ILI incidence } \\
\text { 2. Lab- } \\
\text { confirmed } \\
\text { respira- } \\
\text { tory virus } \\
\text { or influenza } \\
\text { incidence }\end{array}$ & $\begin{array}{l}\text { 1. CRI ( } 3.9 \% \text { vs } 6.7 \%) \text {, } \\
\text { ILI ( } 0.3 \% \text { vs } 0.6 \%) \text {, lab- } \\
\text { confirmed virus ( } 1.4 \% \\
\text { vs } 2.6 \%) \text { and influenza } \\
\text { ( } 0.3 \% \text { vs } 1 \%) \text { rates lower } \\
\text { for N95 compared to } \\
\text { medical masks. } \\
\text { 2. Non-fit-tested N95 } \\
\text { more protective ( } 3.3 \% \\
\text { vs } 6.7 \% \text { ) than medical } \\
\text { masks against CRI only. }\end{array}$ \\
\hline $\begin{array}{l}\text { Macln- } \\
\text { tyre et al. } \\
(61)\end{array}$ & 2013 & $\begin{array}{l}\text { Cluster } \\
\text { RCT }\end{array}$ & 2 & $\begin{array}{l}\text { 1. } \mathrm{CRI}^{\mathrm{c}} \text { or ILI } \\
\text { 2. Lab-confirmed } \\
\text { viral respiratory } \\
\text { infectione }\end{array}$ & $\begin{array}{l}1,669 \mathrm{HCW} \\
\text { in } 19 \text { hospi- } \\
\text { tals }\end{array}$ & $\begin{array}{l}\text { 1. Medical } \\
\text { masks } \\
\text { 2. N95 } \\
\text { 3. Targeted } \\
\text { use of N95 } \\
\text { during } \\
\text { high-risk } \\
\text { procedures }\end{array}$ & $\begin{array}{l}\text { Daily assessment } \\
\text { for respiratory } \\
\text { infections. Swab- } \\
\text { bed if sympto- } \\
\text { matic. }\end{array}$ & $\begin{array}{l}\text { 1. CRI or ILI } \\
\text { incidence } \\
\text { 2. Lab-con- } \\
\text { firmed VRTI } \\
\text { incidence }\end{array}$ & $\begin{array}{l}\text { 1. CRI incidence signifi- } \\
\text { cantly lower with N95 } \\
\text { ( } 7.2 \%) \text { vs. medical mask } \\
(17.1 \%) \text {. } \\
\text { 2. Rate of lab-confirmed } \\
\text { VRTI did not differ } \\
\text { between medical mask } \\
\text { (3.3\%), N95 (2.2\%), and } \\
\text { targeted N95 (3.3\%) } \\
\text { arms. }\end{array}$ \\
\hline $\begin{array}{l}\text { Maclnty- } \\
\text { re et al. }\end{array}$ & 2015 & $\begin{array}{l}\text { Cluster } \\
\text { RCT }\end{array}$ & 2 & $\begin{array}{l}\text { 1. } C R I^{c} \text { or ILI } \\
\text { 2. Lab-confirmed } \\
\text { viral respiratory } \\
\text { infectione }\end{array}$ & $\begin{array}{l}1607 \mathrm{HCWs} \\
\text { working in } \\
\text { high-risk } \\
\text { wards } \\
\text { across } 14 \\
\text { hospitals }\end{array}$ & $\begin{array}{l}\text { 1. Medical } \\
\text { mask } \\
\text { 2. Cloth } \\
\text { mask }\end{array}$ & $\begin{array}{l}\text { Daily assessment } \\
\text { for respiratory } \\
\text { infections. Swab- } \\
\text { bed if sympto- } \\
\text { matic. }\end{array}$ & $\begin{array}{l}\text { 1. CRI or ILI } \\
\text { incidence } \\
\text { 2. Lab-con- } \\
\text { firmed VRTI } \\
\text { incidence }\end{array}$ & $\begin{array}{l}\text { 1. ILI rate higher (RR } 13 \\
[1.69-100.07]) \text { with cloth } \\
\text { vs medical mask. } \\
2 . \text { Lab-confirmed VRTI } \\
\text { rate higher (RR } 1.72 \\
\text { [1.01-2.94]) with cloth vs } \\
\text { medical mask. }\end{array}$ \\
\hline
\end{tabular}

CRI: clinical respiratory illness, HCW: healthcare workers, HS: hand sanitizer, ILI: influenza-like illness, IRR: intervention rate ratio, LOE: level of evidence, PCR: polymerase chain reaction, RCT: randomized controlled trial, RR: relative risk, SAR: secondary attack ratio, VRTI: viral respiratory tract infection. aTemperature $\geq 37.8^{\circ} \mathrm{C}$, history of fever or feeling feverish, $\geq 2$ symptoms (arthralgia, sore throat, cough, sneezing, runny nose, nasal congestion, headache). ' Influenza A and B, RSV, PIV Types 1-3, enteroviruses, rhinoviruses, adenoviruses, coronaviruses 229E and OC43, and hMPV. 'Two or more respiratory or one respiratory symptom and a systemic symptom. ${ }^{\mathrm{d} F e v e r} \geq 38^{\circ} \mathrm{C}$ plus one respiratory symptom (i.e. cough, runny nose, sore throat, etc.). eDetection of adenovirus, human metapneumovirus, coronavirus 229E/NL63/OC43/HKU1, parainfluenza viruses 1, 2, and 3, influenza viruses A and B, respiratory syncytial virus $A$ and $B$, rhinovirus $A / B$. fPresence of cough and $\geq 1$ of fever/feverishness, chills, or body aches. ${ }^{9}$ Subjective (or proven) fever plus one respiratory symptom (e.g. dry or productive cough, runny nose, sore throat, shortness of breath). ${ }^{h}$ Temperature $>37.8^{\circ} \mathrm{C}$ or at least two of the following: sore throat, cough, runny nose, or fatigue.

immune mechanism in healthcare workers and patients who tolerate saline irrigations or are at especially high risk.

\section{Recommendation level: Option}

8. Intervention: Prophylactic nasal washing with saline solution. Optimal frequency, technique, and solution undetermined.

\section{Gargling}

Four unique RCTs evaluating the role of gargling in preventing upper VRTIs were identified (Table 4). Only one ${ }^{(50)}$ was a double-blinded trial, in part due to the difficulty of masking or mimicking the tastes of povidone iodine (PVP-I) and green tea. Satomura et al. ${ }^{(48)}$ conducted a trial in which 387 participants, followed for 60 days, were randomly assigned to three treatment arms: tap water gargling, PVP-I gargling, and usual care (control). Participants in the two intervention arms were instructed to gargle three times per day. All subjects were asked to maintain a gargling diary daily, documenting the frequency of gargling and any URTI complaints. Incident rates were found to be lower in the water gargling cohort ( 0.17 episode/30 person-days) and in the PVP-I gargling cohort (0.24 episode/30-person-days) compared with control ( 0.26 episode/30 person-days). However, on multivariate analysis, gargling with tap water, but not with PVP-I, was found to significantly reduce VRTI incidence (36\% decrease). Although participants were not blinded to the intervention, disease incidence was determined by one study physician who was blinded to the results of assignment. Notably, despite the potential irritant nature of PVP-I, only $2 \%$ of subjects complained of discomfort or difficulties in gargling and withdrew. Three RCTs $s^{(47,49,50)}$ assessed the role of green tea gargling in reducing the incidence of infection during the influenza season. Each study utilized similar gargling regimens (three times daily for 90 days) and the incidence of laboratory-confirmed influenza as the primary endpoint. None of these studies found benefit in 
Table 6. Summary of wearing gloves studies.

\begin{tabular}{|c|c|c|c|c|c|c|c|c|c|}
\hline Study & Year & $\begin{array}{l}\text { Study } \\
\text { Design }\end{array}$ & LOE & Definition of VRTI & $\begin{array}{l}\text { No. of } \\
\text { Subjects }\end{array}$ & Study Group(s) & Study Protocol & $\begin{array}{l}\text { Measured } \\
\text { outcome(s) }\end{array}$ & Conclusion \\
\hline $\begin{array}{l}\text { Chen } \\
\text { et al. }\end{array}$ & 2009 & $\begin{array}{l}\text { Case- } \\
\text { control } \\
\text { study }\end{array}$ & 4 & $\begin{array}{l}\text { 1. Probable SARS } \\
\text { cases }^{\text {a }} \\
\text { 2. SARS IgG positivity }\end{array}$ & $\begin{array}{l}748 \\
\text { HCWs }\end{array}$ & $\begin{array}{l}\text { 1. SARS IgG positive } \\
\text { 2. SARS IgG nega- } \\
\text { tive }\end{array}$ & $\begin{array}{l}\text { Questionnaire: } \\
\text { Quantify pairs } \\
\text { of gloves worn } \\
\text { while caring for } \\
\text { SARS patients. }\end{array}$ & $\begin{array}{l}\text { 1. SARS } \\
\text { infection } \\
\text { rate }\end{array}$ & $\begin{array}{l}4 x \text { higher likelihood } \\
\text { of infection wearing } \\
\text { single pair vs. double } \\
\text { pair. }\end{array}$ \\
\hline $\begin{array}{l}\text { Liu et } \\
\text { al. }\end{array}$ & 2009 & $\begin{array}{l}\text { Case- } \\
\text { control } \\
\text { study }\end{array}$ & 4 & $\begin{array}{l}\text { 1. Probable SARS } \\
\text { cases }^{\text {b }} \\
\text { 2. SARS IgG positivity }\end{array}$ & $\begin{array}{l}477 \\
\text { HCWs }\end{array}$ & $\begin{array}{l}\text { 1. SARS IgG positive } \\
\text { 2. SARS IgG nega- } \\
\text { tive }\end{array}$ & $\begin{array}{l}\text { Questionnaire: } \\
\text { Did participants } \\
\text { wear gloves } \\
\text { during patient } \\
\text { care? }\end{array}$ & $\begin{array}{l}\text { 1. SARS } \\
\text { infection } \\
\text { rate }\end{array}$ & $\begin{array}{l}\text { Gloves significantly } \\
\text { reduced rate }(7.4 \% \\
\text { vs. } 33.3 \%)\end{array}$ \\
\hline $\begin{array}{l}\text { Nishi- } \\
\text { ura et } \\
\text { al. }\end{array}$ & 2005 & $\begin{array}{l}\text { Case- } \\
\text { control } \\
\text { study }\end{array}$ & 4 & $\begin{array}{l}\text { 1. Lab-confirmed } \\
\text { SARS infection }\end{array}$ & $\begin{array}{l}115 \\
\text { HCWs }\end{array}$ & $\begin{array}{l}\text { 1. SARS cases } \\
\text { 2. Individuals with } \\
\text { SARS exposure }\end{array}$ & $\begin{array}{l}\text { Survey: Gloves } \\
\text { worn when in } \\
\text { contact with } \\
\text { SARS patients? }\end{array}$ & $\begin{array}{l}\text { 1. SARS } \\
\text { infection } \\
\text { rate }\end{array}$ & $\begin{array}{l}\text { Wearing gloves did } \\
\text { not decrease likeli- } \\
\text { hood of infection (OR } \\
0.7[0.3-1.9] \text { ). }\end{array}$ \\
\hline $\begin{array}{l}\text { Seto } \\
\text { et al. }\end{array}$ & 2003 & $\begin{array}{l}\text { Case- } \\
\text { control } \\
\text { study }\end{array}$ & 4 & 1. SARS infection ${ }^{c}$ & $\begin{array}{l}254 \\
\text { HCWs }\end{array}$ & $\begin{array}{l}\text { 1. SARS cases } \\
\text { 2. Non-infected } \\
\text { staff with SARS } \\
\text { exposure }\end{array}$ & $\begin{array}{l}\text { Questionnaire: } \\
\text { Were gloves } \\
\text { used during } \\
\text { patient care? }\end{array}$ & $\begin{array}{l}\text { 1. SARS } \\
\text { infection } \\
\text { rate }\end{array}$ & $\begin{array}{l}\text { Wearing gloves did } \\
\text { not decrease likeli- } \\
\text { hood of infection (OR } \\
2 \text { [0.6-7]). }\end{array}$ \\
\hline $\begin{array}{l}\text { Tele- } \\
\text { man } \\
\text { et al. }\end{array}$ & 2004 & $\begin{array}{l}\text { Case- } \\
\text { control } \\
\text { study }\end{array}$ & 4 & $\begin{array}{l}\text { 1. Probable SARS } \\
\text { cases }^{\text {a }} \text {, confirmed } \\
\text { by positive serology } \\
\text { results }\end{array}$ & $86 \mathrm{HCWs}$ & $\begin{array}{l}\text { 1. HCWs with pro- } \\
\text { bable SARS } \\
\text { 2. Non-infected } \\
\text { HCWs with SARS } \\
\text { exposure }\end{array}$ & $\begin{array}{l}\text { Questionnaire: } \\
\text { Glove compli- } \\
\text { ance during } \\
\text { patient contact? }\end{array}$ & $\begin{array}{l}\text { 1. SARS } \\
\text { infection } \\
\text { rate }\end{array}$ & $\begin{array}{l}\text { Wearing gloves did } \\
\text { not decrease likeli- } \\
\text { hood of infection (OR } \\
1.5[0.3-7.2]) \text {. }\end{array}$ \\
\hline $\begin{array}{l}\text { Yin et } \\
\text { al. }\end{array}$ & 2004 & $\begin{array}{l}\text { Case- } \\
\text { control } \\
\text { study }\end{array}$ & 4 & $\begin{array}{l}\text { [Limited information } \\
\text { obtained from partial } \\
\text { translation] }\end{array}$ & $\begin{array}{l}257 \\
\text { HCWs }\end{array}$ & $\begin{array}{l}\text { 1. HCWs with SARS } \\
\text { 2. HCWs without } \\
\text { SARS }\end{array}$ & $\begin{array}{l}\text { Questionnaire: } \\
\text { Glove wearing? }\end{array}$ & $\begin{array}{l}\text { 1. SARS } \\
\text { infection } \\
\text { rate }\end{array}$ & $\begin{array}{l}\text { Wearing gloves } \\
\text { provided significant } \\
\text { protection against } \\
\text { infection. }\end{array}$ \\
\hline
\end{tabular}

HCW: healthcare worker, LOE: level of evidence, OR: odds ratio, SARS: severe acute respiratory syndrome, VRTI: viral respiratory tract infection. a Defined using criteria provided by the China Health Ministry. 'Defined by WHO's criteria. 'Defined as fever of $\geq 380 \mathrm{C}$, radiological infiltrates compatible with pneumonia, and two of chills, new cough, malaise, and signs of consolidation.

gargling with green tea. Each study, however, had noteworthy limitations. Yamada et al. ${ }^{(50)}$ recruited healthy adults inoculated with the influenza vaccine prior to study participation, which may lower the incidence of influenza below what is required to obtain statistical power. Toyoizumi et al..$^{(49)}$ and Ide et al. ${ }^{(47)}$ suffered from low adherence rates $(<75 \%)$ among high school students. When both studies performed a per protocol set analysis, in which non-adherent participants were excluded, the reduction in influenza infection was greater, suggesting that a significant difference in outcomes between the green tea and water gargling groups may be detected in future investigations with greater compliance. In addition, as all four trials were conducted with healthy subjects in Japan, additional studies including different populations with varying sociodemographic characteristics may improve the generalizability of the results.

\section{Summary: Gargling}

1. Aggregate grade of evidence: $C$

2. Benefit: Reduced VRTI transmission

3. Harm: Physical discomfort and potentially taste associated with gargling

4. Cost: Low
5. Benefits-harm assessment: Preponderance of benefit over harm

6. Value judgments: None

7. Recommendation level: Option

8. Intervention: Gargling. Population, optimal frequency, technique, and solution undetermined

\section{Masks}

The efficacy of surgical masks, N95 respirators, and cloth masks in preventing upper VRTI transmission were reviewed (Table 5). The literature search identified 14 unique RCTs for evaluation. All 14 RCTs (level 2 evidence) assessed the use of masks, including surgical masks, $\mathrm{N} 95$ respirators, and cloth masks, as physical barriers. These studies were conducted either in community or healthcare settings.

\section{Surgical masks}

The 8 studies $^{(52-59)}$ that evaluated the use of surgical masks in the community setting failed to clearly demonstrate any benefit. Several studies ${ }^{(54-56,58)}$ were underpowered to detect any statistical difference in primary endpoints between the study groups and 
Table 7. Summary of wearing gowns studies.

\begin{tabular}{|c|c|c|c|c|c|c|c|c|c|}
\hline Study & Year & $\begin{array}{l}\text { Study } \\
\text { Design }\end{array}$ & LOE & Definition of VRTI & $\begin{array}{l}\text { No. of } \\
\text { Subjects }\end{array}$ & Study Group(s) & Study Protocol & $\begin{array}{l}\text { Primary } \\
\text { endpoint(s) }\end{array}$ & Conclusion \\
\hline $\begin{array}{l}\text { Chen } \\
\text { et al. }\end{array}$ & 2009 & $\begin{array}{l}\text { Case- } \\
\text { control } \\
\text { study }\end{array}$ & 4 & $\begin{array}{l}\text { 1. Probable SARS } \\
\text { cases }^{\text {a }} \\
\text { 2. SARS IgG positivity }\end{array}$ & $\begin{array}{l}748 \\
\text { HCWs }\end{array}$ & $\begin{array}{l}\text { 1. SARS IgG positive } \\
\text { 2. SARS IgG nega- } \\
\text { tive }\end{array}$ & $\begin{array}{l}\text { Questionnaire: } \\
\text { Quantify gowns } \\
\text { worn while } \\
\text { caring for SARS } \\
\text { patients. }\end{array}$ & $\begin{array}{l}\text { 1. SARS } \\
\text { infection } \\
\text { rate }\end{array}$ & $\begin{array}{l}\text { Wearing double } \\
\text { gowns not signifi- } \\
\text { cantly more protec- } \\
\text { tive than wearing a } \\
\text { single one. }\end{array}$ \\
\hline $\begin{array}{l}\text { Nishi- } \\
\text { ura et } \\
\text { al. }\end{array}$ & 2005 & $\begin{array}{l}\text { Case- } \\
\text { control } \\
\text { study }\end{array}$ & 4 & $\begin{array}{l}\text { 1. Lab-confirmed } \\
\text { SARS infection }\end{array}$ & $\begin{array}{l}115 \\
\text { HCWs }\end{array}$ & $\begin{array}{l}\text { 1. SARS cases } \\
\text { 2. SARS exposure }\end{array}$ & $\begin{array}{l}\text { Survey: Gowns } \\
\text { worn when in } \\
\text { contact with } \\
\text { SARS patients? }\end{array}$ & $\begin{array}{l}\text { 1. SARS } \\
\text { infection } \\
\text { rate }\end{array}$ & $\begin{array}{l}\text { Use of gowns lowe- } \\
\text { red rate by } 80 \% \text {. }\end{array}$ \\
\hline $\begin{array}{l}\text { Seto } \\
\text { et al. }\end{array}$ & 2003 & $\begin{array}{l}\text { Case- } \\
\text { control } \\
\text { study }\end{array}$ & 4 & 1. SARS infection ${ }^{b}$ & $\begin{array}{l}254 \\
\mathrm{HCWs}\end{array}$ & $\begin{array}{l}\text { 1. SARS cases } \\
\text { 2. SARS exposure }\end{array}$ & $\begin{array}{l}\text { Questionnaire: } \\
\text { Were gowns } \\
\text { used during } \\
\text { patient care? }\end{array}$ & $\begin{array}{l}\text { 1. SARS } \\
\text { infection } \\
\text { rate }\end{array}$ & $\begin{array}{l}\text { Gown use signi- } \\
\text { ficantly differed } \\
\text { between infected } \\
(0 \%) \text { and non-infec- } \\
\text { ted (34\%) staff. }\end{array}$ \\
\hline $\begin{array}{l}\text { Tele- } \\
\text { man } \\
\text { et al. }\end{array}$ & 2004 & $\begin{array}{l}\text { Case- } \\
\text { control } \\
\text { study }\end{array}$ & 4 & $\begin{array}{l}\text { 1. Probable SARS } \\
\text { cases }^{c} \text {, confirmed } \\
\text { by positive serology } \\
\text { results }\end{array}$ & $86 \mathrm{HCWs}$ & $\begin{array}{l}\text { 1. HCWs with pro- } \\
\text { bable SARS } \\
\text { 2. HCWs with SARS } \\
\text { exposure }\end{array}$ & $\begin{array}{l}\text { Questionnaire: } \\
\text { Gown compli- } \\
\text { ance during } \\
\text { patient contact? }\end{array}$ & $\begin{array}{l}\text { 1. SARS } \\
\text { infection } \\
\text { rate }\end{array}$ & $\begin{array}{l}\text { Gowns not signifi- } \\
\text { cantly protective (OR } \\
0.5[0.4-6.9] \text {. }\end{array}$ \\
\hline $\begin{array}{l}\text { Yin et } \\
\text { al. }\end{array}$ & 2004 & $\begin{array}{l}\text { Case- } \\
\text { control } \\
\text { study }\end{array}$ & 4 & $\begin{array}{l}\text { [Limited information } \\
\text { obtained from partial } \\
\text { translation] }\end{array}$ & $\begin{array}{l}257 \\
\text { HCWs }\end{array}$ & $\begin{array}{l}\text { 1. HCWs with SARS } \\
\text { 2. HCWs without } \\
\text { SARS }\end{array}$ & $\begin{array}{l}\text { Questionnaire: } \\
\text { Gown wearing? }\end{array}$ & $\begin{array}{l}\text { 1. SARS } \\
\text { infection } \\
\text { rate }\end{array}$ & $\begin{array}{l}\text { Wearing a gown } \\
\text { provided significant } \\
\text { protection against } \\
\text { SARS infection. }\end{array}$ \\
\hline
\end{tabular}

HCW: healthcare workers, LOE: level of evidence, OR: odds ratio, SARS: severe acute respiratory syndrome, VRTI: viral respiratory tract infection. a Defined using criteria provided by the China Health Ministry. ${ }^{b}$ Defined as fever of $\geq 38^{\circ} \mathrm{C}$, radiological infiltrates compatible with pneumonia, and two of: chills, new cough, malaise, and signs of consolidation. 'Defined by WHO's criteria.

thus failed to report conclusive findings on their efficacy in preventing viral transmission in community settings. Of note, the trial conducted by Canini et al. ${ }^{(55)}$ was severely underpowered due to premature termination of the study. Maclntyre et al. ${ }^{(57)}$ cited poor compliance $(<50 \%)$ as one of the main limitations of the study, concluding that without the threat of an epidemic or pandemic to encourage greater adherence, household use of face masks would be ineffective for controlling seasonal respiratory disease.

In contrast to earlier studies that sought to ascertain the impact of mask use in preventing secondary viral transmission, Aiello et al. designed two studies ${ }^{(52,53)}$ to examine their effectiveness when implemented prior to the onset of influenza-like illness symptoms. In both trials, students living in residence houses were assigned to one of three arms: face mask and hand hygiene, face mask only, or control. Using the rate of VRTI as the primary endpoint, Aiello et al. reached the same conclusion in both studies: neither intervention was associated with a significant reduction cumulatively during the 6-week study period. Despite these findings, the significance of these two trials lies in their study design, which more accurately represents guidelines that recommend the use of NPIs before susceptible individuals become infected and an outbreak ensues.

In healthcare settings, evidence on the efficacy of surgical masks in preventing upper VRTI transmission was similarly inconclu- sive. In two studies ${ }^{(61,63)}$, although the incidence of VRTI was higher among healthcare workers in the no-mask group, the difference was not significant. However, both studies reported limitations, including lack of randomization of the control arm ${ }^{(61)}$ and a small sample size $(\mathrm{n}=32)^{(63)}$.

\section{N95 Respirators}

Evidence supporting the use of N95 respirators for preventing viral transmission was stronger in healthcare than in community settings. Among the studies conducted in the community, only one $^{(57)}$ assessed its effectiveness relative to surgical masks and no masks. Although the secondary attack rate in exposed adults did not significantly differ among the three study arms, the trial suffered from low compliance as previously mentioned. In addition, a small sample size precluded any conclusive comparison of the relative efficacy of $\mathrm{N} 95$ respirators and surgical masks. Four RCTs assessed the efficacy of N95 respirators when utilized by healthcare workers. Maclntyre et al. demonstrated in two separate trials ${ }^{(60,61)}$ that $\mathrm{N} 95$ respirators were superior to medical masks in preventing clinical respiratory illness despite the greater discomfort and lower adherence associated with respirator use. Moreover, to observe this benefit, healthcare workers had to wear the respirator consistently during the entirety of their shifts rather than intermittently. In contrast, two studies ${ }^{(64,65)}$ reported no significant difference in VRTI incidence between 
Table 8. Summary of wearing eye protection (mask/goggles) studies.

\begin{tabular}{|c|c|c|c|c|c|c|c|c|c|}
\hline Study & Year & $\begin{array}{l}\text { Study } \\
\text { Design }\end{array}$ & LOE & Definition of VRTI & $\begin{array}{l}\text { No. of } \\
\text { Subjects }\end{array}$ & Study Group(s) & Study Protocol & $\begin{array}{l}\text { Primary } \\
\text { endpoint(s) }\end{array}$ & Conclusion \\
\hline $\begin{array}{l}\text { Chen } \\
\text { et al. }\end{array}$ & 2009 & $\begin{array}{l}\text { Case- } \\
\text { control } \\
\text { study }\end{array}$ & 4 & $\begin{array}{l}\text { 1. Probable SARS } \\
\text { cases }^{\text {a }} \\
\text { 2. SARS IgG positivity }\end{array}$ & $\begin{array}{l}748 \\
\text { HCWs }\end{array}$ & $\begin{array}{l}\text { 1. SARS IgG positive } \\
\text { 2. SARS IgG nega- } \\
\text { tive }\end{array}$ & $\begin{array}{l}\text { Question- } \\
\text { naire: Quan- } \\
\text { tify frequency of } \\
\text { wearing goggles } \\
\text { while caring for } \\
\text { SARS patients. }\end{array}$ & $\begin{array}{l}\text { 1. SARS } \\
\text { infection } \\
\text { rate }\end{array}$ & $\begin{array}{l}\text { Frequency of wea- } \\
\text { ring goggles did not } \\
\text { significantly reduce } \\
\text { infection rate. }\end{array}$ \\
\hline $\begin{array}{l}\text { Liu et } \\
\text { al. }\end{array}$ & 2009 & $\begin{array}{l}\text { Case- } \\
\text { control } \\
\text { study }\end{array}$ & 4 & $\begin{array}{l}\text { 1. Probable SARS } \\
\text { cases }^{b} \\
\text { 2. SARS IgG positivity }\end{array}$ & $\begin{array}{l}477 \\
\text { HCWs }\end{array}$ & $\begin{array}{l}\text { 1. SARS IgG positive } \\
\text { 2. SARS IgG nega- } \\
\text { tive }\end{array}$ & $\begin{array}{l}\text { Questionnaire: } \\
\text { Did participants } \\
\text { wear goggles } \\
\text { during patient } \\
\text { care? }\end{array}$ & $\begin{array}{l}\text { 1. SARS } \\
\text { infection } \\
\text { rate }\end{array}$ & $\begin{array}{l}\text { Wearing goggles } \\
\text { significantly reduced } \\
\text { rate }(7.7 \% \text { vs. } 13.3 \%) \text {. }\end{array}$ \\
\hline $\begin{array}{l}\text { Yin et } \\
\text { al. }\end{array}$ & 2004 & $\begin{array}{l}\text { Case- } \\
\text { control } \\
\text { study }\end{array}$ & 4 & $\begin{array}{l}\text { [Limited information } \\
\text { obtained from partial } \\
\text { translation] }\end{array}$ & $\begin{array}{l}257 \\
\text { HCWs }\end{array}$ & $\begin{array}{l}\text { 1. HCWs with SARS } \\
\text { 2. HCWs without } \\
\text { SARS }\end{array}$ & $\begin{array}{l}\text { Questionnaire: } \\
\text { Goggle wearing? }\end{array}$ & $\begin{array}{l}\text { 1. SARS } \\
\text { infection } \\
\text { rate }\end{array}$ & $\begin{array}{l}\text { Wearing goggles } \\
\text { reduced odds of } \\
\text { infection (OR } 0.20 \\
[0.10-0.41]) .\end{array}$ \\
\hline
\end{tabular}

HCW: healthcare workers, LOE: level of evidence, OR: odds ratio, SARS: severe acute respiratory syndrome, VRTI: viral respiratory tract infection. ${ }^{\text {DDe- }}$ fined using criteria provided by the China Health Ministry. ${ }^{\circ}$ Defined by WHO's criteria.

the two interventions. The study conducted by Loeb et al. ${ }^{(64)}$ had several limitations, including small sample size $(n=446)$, lack of control arm, and the use of serology to confirm influenza infection. Despite recruiting more patients $(n=4,051)$ and utilizing both clinical symptoms and laboratory confirmation to reach the diagnosis, Radonovich et al. ${ }^{(65)}$ similarly found no difference in primary endpoints.

\section{Cloth masks}

The efficacy of cloth masks was evaluated in one trial ${ }^{(62)}$, which found that the rate of VRTI was significantly higher among healthcare workers wearing cloth masks compared with those using medical masks, likely because the penetration of particles through the cloth masks was found to be very high (97\%).

\section{Summary: Masks}

\section{For Community Settings:}

1. Aggregate grade of evidence: $B$

2. Benefit: Reduced VRTI transmission

3. Harm: Discomfort while wearing, more protective masks may lead to increased user discomfort.

4. Cost: Variable; low cost of materials in setting of normal demand, but may increase substantially in setting of reduced supply. Fit testing for respirators.

5. Benefits-harm assessment: Preponderance of benefit over harm

6. Value judgments: High value to prevent community spread in setting of high risk of exposure, with partially diminished value in lower risk, community settings

7. Recommendation level: Recommendation

8. Intervention: Donning masks. Optimal mask type undetermined due to varying efficacy.

\section{For Healthcare Settings:}

1. Aggregate grade of evidence: $A$

2. Benefit: Reduced VRTI transmission

3. Harm: Discomfort while wearing; lower compliance of respirators as compared to other masks

4. Cost: Variable; low cost of materials in setting of normal demand, but may increase substantially in setting of reduced supply

5. Benefits-harm assessment: Preponderance of benefit over harm

6. Value judgments: Potential exceedingly high value in high risk, healthcare settings

7. Recommendation level: Strong recommendation

8. Intervention: Donning masks. Optimal mask type undetermined. Respirators are warranted for high risk scenarios, though continuous use is associated with discomfort and risk of lower compliance. Cloth masks are not recommended in the clinical setting.

\section{Gloves, Gowns, and Eye Protection}

Because no RCTs assessing the use of gloves, gowns, and eye protection in preventing upper VRTI transmission were identified, available evidence derived from case-control studies was evaluated (Tables 6-8). All six studies recruited healthcare workers who cared for SARS patients during the outbreak in 2003, retrospectively assessing their compliance with PPE usage via questionnaires. The incidence of SARS infection among participants was used as the measured outcome. Of the six casecontrol $^{(41-46)}$ studies on glove-wearing, half of them reported no significant benefit in donning gloves to reduce viral transmission. Five case-control studies ${ }^{(41,43-46)}$ on gown-wearing simi- 
Table 9. Summary of social distancing studies.

\begin{tabular}{|c|c|c|c|c|c|c|c|c|c|}
\hline Study & Year & $\begin{array}{l}\text { Study } \\
\text { Design }\end{array}$ & LOE & Definition of VRTI & $\begin{array}{l}\text { No. of } \\
\text { Subjects }\end{array}$ & Study Group(s) & Study Protocol & $\begin{array}{l}\text { Primary } \\
\text { endpoint(s) }\end{array}$ & Conclusion \\
\hline Miyaki & 2011 & $\begin{array}{l}\text { Quasi- } \\
\text { cluster } \\
\text { RCT }\end{array}$ & 2 & $\begin{array}{l}\text { 1. ILI } \\
\text { 2. Positive result } \\
\text { from rapid testing of } \\
\text { influenza } A\end{array}$ & $\begin{array}{l}15,134 \\
\text { company } \\
\text { employ- } \\
\text { ees }\end{array}$ & $\begin{array}{l}\text { 1. Social distancing } \\
\text { 2. No social distan- } \\
\text { cing }\end{array}$ & $\begin{array}{l}\text { Employees of } \\
\text { family members } \\
\text { with ILI stayed } \\
\text { home. Control } \\
\text { subjects repor- } \\
\text { ted to work, } \\
\text { even if contact } \\
\text { developed ILI. }\end{array}$ & $\begin{array}{l}\text { 1. Incidence } \\
\text { of influenza } \\
\text { A H1N1 }\end{array}$ & $\begin{array}{l}\text { Overall risk of } \\
\text { infection was sig- } \\
\text { nificantly reduced } \\
\text { ( } 20 \%) \text { by interven- } \\
\text { tion. }\end{array}$ \\
\hline
\end{tabular}

ILI: influenza-like illness, LOE: level of evidence, RCT: randomized controlled trial VRTI: viral respiratory tract infection. ${ }^{\mathrm{a}}$ Temperature $>38^{\circ} \mathrm{C}$ or more than $1^{\circ} \mathrm{C}$ above the normal temperature accompanied with more than 2 of these symptoms: nasal mucus, pharyngeal pain, cough, chills or heat sensation.

larly provided conflicting evidence, with three demonstrating benefit. Finally, of three case-control studies ${ }^{(41,42,46)}$ on utilizing eye protection, two determined that the use of eye masks or goggles conferred a protective effect against viral infection for healthcare workers. As previously mentioned, nuanced and cautious interpretation of the relatively lower quality evidence derived from case-control studies was undertaken.

\section{Summary: Gloves, gowns, and eye protection}

1. Aggregate grade of evidence: $C$

2. Benefit: Reduced VRTI transmission

3. Harm: Discomfort, minimal

4. Cost: Low, cost of materials, which may be fluid during supply shortages of large viral outbreaks

5. Benefits-harm assessment: Preponderance of benefit over harm, as there is (limited) evidence to support benefit, but definitely zero evidence to support harm

6. Value judgments: With limited evidence to support benefit of use, and no evidence of potential harm, this intervention has potential for high value in the analysed healthcare setting

7. Recommendation level: Recommendation in healthcare setting

8. Intervention: Donning PPE for healthcare workers. Differences in efficacy of gloves, gowns, and eye protection could not be determined.

\section{Social distancing}

One quasi-cluster RCT (level 2 evidence) was reviewed (Table 9). Miyaki et al. ${ }^{(51)}$ evaluated the effectiveness of social distancing in workplaces, utilizing the incidence of influenza A H1N1 as the primary endpoint. Company employees in the intervention arm were asked to remain home if a co-habitating family member developed a VRTI while those in the control group reported to work as usual if the same situation occurred. Following the 233day study period, the authors demonstrated that implementation of a stay-at-home policy significantly reduced the overall risk of influenza infection in the workplace by $20 \%$. Full compliance was achieved among those following social distancing protocol, likely because employees continued to receive full pay while at home and were explained about its public health benefit. Therefore, the authors regarded promoting a public health mindset and offering financial support as important measures to maintain high adherence to social distancing policies. An aggregate level of evidence is not provided for this level 2 study, however, its findings are notable, including the potential for reduced VRTI transmission. Potential harm and cost include reduced productivity, especially if workers lose compensation or cannot work from home. Despite potential financial and psychosocial risks when implemented over long periods, there appears to be high value of this intervention, especially when employed in the acute infectious period. Based on the available evidence, the authors recommend social distancing protocols with measures to mitigate productivity and compensation loss (e.g. ability to work remotely).

\section{Hand hygiene}

The literature search identified 29 unique RCTs (level 2 evidence) for review (Table 10). Heterogeneity of settings, hand hygiene interventions, and primary endpoints existed across studies. Nine studies ${ }^{(66-74)}$ were conducted in elementary schools, of which six ${ }^{(66-71)}$ reported a significant reduction in VRTI-associated absenteeism in the intervention arm compared with control. To elucidate the reported effect of hand hygiene on reducing viral transmission, the interventions studied were stratified into three broad categories to allow for comparison: those that mainly promoted hand sanitizer use, those that emphasized soap use, and those that provided education only. Four trials studied the effect of hand sanitizer (alcohol-based or alcohol-free) use alone but because this intervention was offered at different times throughout the school day, a comparison of outcomes was challenging. Of the three studies that tested the effect of an alcohol-based handrub alone, two ${ }^{(67,68)}$ reported a significant re- 
Table 10. Summary of hand hygiene studies.

\begin{tabular}{|c|c|c|c|c|c|c|c|c|c|}
\hline Study & Year & $\begin{array}{l}\text { Study } \\
\text { Design }\end{array}$ & LOE & Definition of VRTI & $\begin{array}{l}\text { No. of } \\
\text { Subjects }\end{array}$ & $\begin{array}{l}\text { Study } \\
\text { Group(s) }\end{array}$ & Study Protocol & $\begin{array}{l}\text { Primary } \\
\text { endpoint(s) }\end{array}$ & Conclusion \\
\hline $\begin{array}{l}\text { Cowling } \\
\text { et al. }\end{array}$ & 2009 & $\begin{array}{l}\text { Cluster } \\
\text { RCT }\end{array}$ & 2 & $\begin{array}{l}\text { 1. Lab evidence of } \\
\text { influenza OR } \\
\text { 2. } \geq 2 \text { of the fol- } \\
\text { lowing: tempera- } \\
\text { ture }>37.8^{\circ} \mathrm{C} \text {, cough, } \\
\text { headache, sore } \\
\text { throat, myalgia OR } \\
\text { 3. Temperature } \\
>37.8^{\circ} \mathrm{C} \text { plus cough } \\
\text { or sore throat }\end{array}$ & $\begin{array}{l}\text { 1,201 (407 } \\
\text { index patients, } \\
794 \text { household } \\
\text { contacts) }\end{array}$ & $\begin{array}{l}\text { 1. Hand } \\
\text { hygiene + } \\
\text { education } \\
\text { 2. Lifestyle } \\
\text { education }\end{array}$ & $\begin{array}{l}\text { All household } \\
\text { contacts kept } \\
\text { daily symp- } \\
\text { tom diaries. } \\
\text { Nasal and throat } \\
\text { swabs collected } \\
\text { at home visits. }\end{array}$ & $\begin{array}{l}\text { 1. SAR } \\
\text { among } \\
\text { household } \\
\text { contacts }\end{array}$ & $\begin{array}{l}\text { No significant } \\
\text { difference in SAR } \\
\text { between inter- } \\
\text { vention (14\%) and } \\
\text { control (24\%). }\end{array}$ \\
\hline $\begin{array}{l}\text { Sim- } \\
\text { merman } \\
\text { et al. }\end{array}$ & 2011 & $\begin{array}{l}\text { Cluster } \\
\text { RCT }\end{array}$ & 2 & $\begin{array}{l}\text { 1. ILI }{ }^{\mathrm{a}} \\
\text { 2. Lab-confirmed } \\
\text { influenza }\end{array}$ & 885 subjects & $\begin{array}{l}\text { 1. Handwa- } \\
\text { shing } \\
\text { 2. Education }\end{array}$ & $\begin{array}{l}\text { Respiratory } \\
\text { swabs and se- } \\
\text { rum collected } \\
\text { from all house- } \\
\text { hold members. }\end{array}$ & $\begin{array}{l}\text { 1. SAR } \\
\text { among } \\
\text { household } \\
\text { contacts }\end{array}$ & $\begin{array}{l}\text { SAR not reduced } \\
\text { by promotion } \\
\text { of handwashing } \\
(23 \%) \text { vs. control } \\
(19 \%) .\end{array}$ \\
\hline $\begin{array}{l}\text { Larson } \\
\text { et al. }\end{array}$ & 2010 & $\begin{array}{l}\text { Cluster } \\
\text { block } \\
\text { RCT }\end{array}$ & 2 & $\begin{array}{l}\text { 1. ILI: Temperature of } \\
>37.8^{\circ} \mathrm{C} \text { and cough } \\
\text { and/or sore throat } \\
\text { 2. URI: Not specified }\end{array}$ & $\begin{array}{l}2788 \text { partici- } \\
\text { pants in } 617 \\
\text { households }\end{array}$ & $\begin{array}{l}\text { 1. Alcohol- } \\
\text { based HS + } \\
\text { education } \\
\text { 2. Education }\end{array}$ & $\begin{array}{l}\text { Presence or } \\
\text { absence of } \\
\text { symptoms } \\
\text { reported for } \\
\text { every household } \\
\text { member. }\end{array}$ & $\begin{array}{l}\text { 1. Incidence } \\
\text { and secon- } \\
\text { dary trans- } \\
\text { mission of } \\
\text { VRTI }\end{array}$ & $\begin{array}{l}\text { No reduction in } \\
\text { incidence ( } 29 \% \\
\text { vs. } 35 \%) \text { or SAR } \\
\text { ( } 14.4 \% \text { vs. } 13.7 \%) \\
\text { with HS. }\end{array}$ \\
\hline $\begin{array}{l}\text { Priest } \\
\text { et al. }\end{array}$ & 2014 & $\begin{array}{l}\text { Cluster } \\
\text { RCT }\end{array}$ & 2 & $\begin{array}{l}\text { Runny, stuffy, or } \\
\text { blocked nose, noisy } \\
\text { breathing, cough, } \\
\text { fever, sore throat or } \\
\text { sneezing }^{\text {b }}\end{array}$ & 2443 students & $\begin{array}{l}\text { 1. Alcohol- } \\
\text { based HS + } \\
\text { education } \\
\text { 2. Hand hygie- } \\
\text { ne education }\end{array}$ & $\begin{array}{l}\text { Absence infor- } \\
\text { mation of child- } \\
\text { ren collected. }\end{array}$ & $\begin{array}{l}\text { 1. Absence } \\
\text { episodes } \\
\text { per } 100 \\
\text { child-days. }\end{array}$ & $\begin{array}{l}\text { Absence episodes } \\
\text { not significantly } \\
\text { different with HS } \\
\text { (1.21) vs. control } \\
\text { (1.16). }\end{array}$ \\
\hline $\begin{array}{l}\text { Sandora } \\
\text { et al. }\end{array}$ & 2008 & $\begin{array}{l}\text { Cluster } \\
\text { RCT }\end{array}$ & 2 & $\begin{array}{l}\text { Runny, stuffy, or } \\
\text { blocked nose, cough, } \\
\text { fever or chills, sore } \\
\text { throat, or sneezing. }\end{array}$ & 285 students & $\begin{array}{l}\text { 1. Alcohol- } \\
\text { based HS } \\
\text { 2. Usual prac- } \\
\text { tices }\end{array}$ & $\begin{array}{l}\text { Reason for ab- } \\
\text { sence recorded } \\
\text { on a standardi- } \\
\text { zed form. }\end{array}$ & $\begin{array}{l}\text { 1. Rate of } \\
\text { school ab- } \\
\text { senteeism }\end{array}$ & $\begin{array}{l}\text { No significant im- } \\
\text { pact on rate ratio } \\
(1.07 \text { [0.92-1.24]) } \\
\text { with HS. }\end{array}$ \\
\hline $\begin{array}{l}\text { Steb- } \\
\text { bins et } \\
\text { al. }\end{array}$ & 2011 & $\begin{array}{l}\text { Cluster } \\
\text { RCT }\end{array}$ & 2 & $\begin{array}{l}\text { ILI: fever } \geq 38^{\circ} \mathrm{C} \text { with } \\
\text { sore throat or cough }\end{array}$ & 3360 students & $\begin{array}{l}\text { 1. HS + edu- } \\
\text { cation } \\
\text { 2. Standard } \\
\text { practice }\end{array}$ & $\begin{array}{l}\text { Student absen- } \\
\text { teeism recorded. }\end{array}$ & $\begin{array}{l}\text { 1. Absence } \\
\text { episodes }\end{array}$ & $\begin{array}{l}\text { No significant } \\
\text { effect of inter- } \\
\text { vention (IRR } 0.81 \\
[0.54-1.23]) \text {. }\end{array}$ \\
\hline $\begin{array}{l}\text { Bowen } \\
\text { et al. }\end{array}$ & 2007 & $\begin{array}{l}\text { Cluster } \\
\text { RCT }\end{array}$ & 2 & $\begin{array}{l}\text { Conjunctivitis, otal- } \\
\text { gia, rhinorrhoea, sore } \\
\text { throat, or cough. }\end{array}$ & $\begin{array}{l}3962 \text { students } \\
\text { in } 87 \text { groups }\end{array}$ & $\begin{array}{l}\text { 1. Soap + } \\
\text { education } \\
\text { 2. Education } \\
\text { 3. Standard } \\
\text { practice }\end{array}$ & $\begin{array}{l}\text { Symptoms or } \\
\text { signs of illness } \\
\text { identified by } \\
\text { teachers. }\end{array}$ & $\begin{array}{l}\text { 1. ARI- } \\
\text { related ab- } \\
\text { senteeism } \\
\text { 2. ARI illness } \\
\text { rate }\end{array}$ & $\begin{array}{l}\text { Significant } \\
\text { reductions in } \\
\text { absenteeism ( } 1.2 \\
\text { vs. } 2.6 \text { d) and rate } \\
\text { ( } 1.2 \text { vs. } 2 \text { episodes) } \\
\text { with soap use + } \\
\text { education only. }\end{array}$ \\
\hline $\begin{array}{l}\text { Patel et } \\
\text { al. }\end{array}$ & 2012 & $\begin{array}{l}\text { Cluster } \\
\text { RCT }\end{array}$ & 2 & $\begin{array}{l}\text { ARI: reported fever } \\
\text { and cough or dif- } \\
\text { ficulty breathing }\end{array}$ & $\begin{array}{l}43 \text { schools and } \\
643 \text { house- } \\
\text { holds }\end{array}$ & $\begin{array}{l}\text { 1. Handwa- } \\
\text { shing } \\
\text { + education } \\
\text { 2. Standard } \\
\text { practice }\end{array}$ & $\begin{array}{l}\text { ARI assessed for } \\
\text { and recorded. }\end{array}$ & $\begin{array}{l}\text { 1. ARI illness } \\
\text { rate }\end{array}$ & $\begin{array}{l}\text { Significant rate } \\
\text { reduction with } \\
\text { handwashing vs. } \\
\text { control ( } 2 \% \text { vs. } \\
3 \%) \text {. }\end{array}$ \\
\hline $\begin{array}{l}\text { Picke- } \\
\text { ring et } \\
\text { al. }\end{array}$ & 2013 & $\begin{array}{l}\text { Cluster } \\
\text { RCT }\end{array}$ & 2 & $\begin{array}{l}\text { Symptoms of cough, } \\
\text { difficulty breathing, } \\
\text { sore throat, rhinor- } \\
\text { rhoea }\end{array}$ & 1,364 students & $\begin{array}{l}\text { 1. Soap } \\
\text { 2. Alcohol- } \\
\text { based HS } \\
\text { 3. Standard } \\
\text { practice }\end{array}$ & $\begin{array}{l}\text { Students inter- } \\
\text { viewed weekly } \\
\text { regarding } \\
\text { symptoms. }\end{array}$ & $\begin{array}{l}\text { 1. ARI illness } \\
\text { rate } \\
\text { 2. ARI- } \\
\text { associated } \\
\text { school ab- } \\
\text { senteeism }\end{array}$ & $\begin{array}{l}\text { 1. Soap and HS } \\
\text { use reduced } \\
\text { illness, each by } \\
23 \% \text {. } \\
2 . \text { Only HS use } \\
\text { significantly } \\
\text { reduced likelihood } \\
\text { of absenteeism by } \\
49 \% \text {. }\end{array}$ \\
\hline
\end{tabular}




\begin{tabular}{|c|c|c|c|c|c|c|c|c|c|}
\hline Study & Year & $\begin{array}{l}\text { Study } \\
\text { Design }\end{array}$ & LOE & Definition of VRTI & $\begin{array}{l}\text { No. of } \\
\text { Subjects }\end{array}$ & $\begin{array}{l}\text { Study } \\
\text { Group(s) }\end{array}$ & Study Protocol & $\begin{array}{l}\text { Primary } \\
\text { endpoint(s) }\end{array}$ & Conclusion \\
\hline $\begin{array}{l}\text { White } \\
\text { et al. }\end{array}$ & 2001 & $\begin{array}{l}\text { Dou- } \\
\text { ble- } \\
\text { blin- } \\
\text { ded, } \\
\text { pla- } \\
\text { cebo- } \\
\text { con- } \\
\text { trolled } \\
\text { cluster } \\
\text { RCT }\end{array}$ & 2 & $\begin{array}{l}\text { Symptoms of cough, } \\
\text { sneezing, sinus trou- } \\
\text { ble, bronchitis, fever, } \\
\text { pink-eye, headache, } \\
\text { mononucleosis }\end{array}$ & 769 students & $\begin{array}{l}\text { 1. Alcohol-free } \\
\text { HS } \\
\text { 2. Placebo }\end{array}$ & $\begin{array}{l}\text { Daily attendance } \\
\text { and nature of } \\
\text { student's ab- } \\
\text { sence recorded. }\end{array}$ & $\begin{array}{l}\text { 1. Illness } \\
\text { absence } \\
\text { incidence }\end{array}$ & $\begin{array}{l}\text { HS significantly } \\
\text { decreased likeli- } \\
\text { hood of absence } \\
\text { by } 31 \% \text {. }\end{array}$ \\
\hline $\begin{array}{l}\text { Talaat } \\
\text { et al. }\end{array}$ & 2011 & $\begin{array}{l}\text { Cluster } \\
\text { RCT }\end{array}$ & 2 & $\begin{array}{l}\text { 1. ILI: fever }>38^{\circ} \mathrm{C}+ \\
\text { cough or sore throat } \\
\text { 2. Lab-confirmed } \\
\text { influenza }\end{array}$ & $\begin{array}{l}44,451 \text { stu- } \\
\text { dents }\end{array}$ & $\begin{array}{l}\text { 1. Soap + } \\
\text { education } \\
\text { 2. Standard } \\
\text { practice }\end{array}$ & $\begin{array}{l}\text { Absences due to } \\
\text { illness recorded. }\end{array}$ & $\begin{array}{l}\text { 1. Absences } \\
\text { due to } \\
\text { illness }\end{array}$ & $\begin{array}{l}\text { Absenteeism sig- } \\
\text { nificantly reduced } \\
\text { by } 40-50 \% \text {. }\end{array}$ \\
\hline $\begin{array}{l}\text { Pandej- } \\
\text { pong et } \\
\text { al. }\end{array}$ & 2012 & $\begin{array}{l}\text { Cluster } \\
\text { RCT }\end{array}$ & 2 & $\begin{array}{l}\text { Runny/stuffy } \\
\text { nose, cough, fever, } \\
\text { chills, sore throat, } \\
\text { headache, hand-foot- } \\
\text { mouth ulcers }\end{array}$ & 1,437 students & $\begin{array}{l}\text { 1. HS every } 60 \\
\text { min. } \\
\text { 2. HS every } \\
120 \text { min. } \\
\text { 3. HS before } \\
\text { lunch }\end{array}$ & $\begin{array}{l}\text { Absences } \\
\text { caused by ILI } \\
\text { recorded. }\end{array}$ & $\begin{array}{l}\text { 1. Change in } \\
\text { absentee- } \\
\text { ism rate }\end{array}$ & $\begin{array}{l}\text { Rate significantly } \\
\text { lowered with HS } \\
\text { every } 60 \text { min. } \\
(1.7 \%) \text {, but not } \\
120 \text { min. }(2.5 \%) \text {, } \\
\text { vs. control }(2.6 \%)\end{array}$ \\
\hline $\begin{array}{l}\text { Kotch } \\
\text { et al. }\end{array}$ & 1994 & $\begin{array}{l}\text { Cluster } \\
\text { RCT }\end{array}$ & 2 & $\begin{array}{l}\text { Symptoms of } \\
\text { coughing, runny } \\
\text { nose, wheezing, sore } \\
\text { throat, or earache }\end{array}$ & $\begin{array}{l}389 \text { children } \\
\text { in } 24 \text { childcare } \\
\text { centres }\end{array}$ & $\begin{array}{l}\text { 1. Handwa- } \\
\text { shing training } \\
\text { 2. No training }\end{array}$ & $\begin{array}{l}\text { Respiratory } \\
\text { symptoms eli- } \\
\text { cited. }\end{array}$ & $\begin{array}{l}\text { 1. Inci- } \\
\text { dence of } \\
\text { respiratory } \\
\text { episodes }\end{array}$ & $\begin{array}{l}\text { No reduction in } \\
\text { incidence (RR } 0.94 \\
[-2.43-0.66]) \text {. }\end{array}$ \\
\hline $\begin{array}{l}\text { Sandora } \\
\text { et al. }\end{array}$ & 2005 & $\begin{array}{l}\text { Cluster } \\
\mathrm{RCT}\end{array}$ & 2 & $\begin{array}{l}2 \text { of the following: } \\
\text { runny nose, stuffy/ } \\
\text { blocked nose, noisy } \\
\text { breathing, cough, fe- } \\
\text { ver/chills, sore throat, } \\
\text { sneezing }\end{array}$ & $\begin{array}{l}292 \text { families } \\
\text { with children } \\
\text { enrolled in } \\
\text { childcare } \\
\text { centres }\end{array}$ & $\begin{array}{l}\text { 1. Alcohol- } \\
\text { based HS + } \\
\text { education } \\
\text { 2. Education } \\
\text { only }\end{array}$ & $\begin{array}{l}\text { Self-reported } \\
\text { symptoms col- } \\
\text { lected. }\end{array}$ & $\begin{array}{l}\text { 1. Weekly } \\
\text { preva- } \\
\text { lence of RTI } \\
\text { symptoms }\end{array}$ & $\begin{array}{l}\text { No risk reduction } \\
\text { with soap (RR 0.8, } \\
[0.66-1.03]) \text { or } \\
\text { alcohol rub (RR } \\
0.96,[0.76-1.20]) \\
\text { vs. control. }\end{array}$ \\
\hline $\begin{array}{l}\text { Hovi et } \\
\text { al. }\end{array}$ & 2017 & $\begin{array}{l}\text { Cluster } \\
\text { RCT }\end{array}$ & 2 & $\begin{array}{l}\text { "Symptoms typical of } \\
\text { acute RTI" }\end{array}$ & $\begin{array}{l}683 \text { office } \\
\text { employees }\end{array}$ & $\begin{array}{l}\text { 1. Plain soap } \\
\text { 2. Antibacte- } \\
\text { rial soap }\end{array}$ & $\begin{array}{l}\text { Self-reported } \\
\text { symptoms col- } \\
\text { lected. }\end{array}$ & $\begin{array}{l}\text { 1. Weekly } \\
\text { preva- } \\
\text { lence of RTI } \\
\text { symptoms }\end{array}$ & $\begin{array}{l}\text { No risk reduction } \\
\text { with soap (RR 0.8, } \\
[0.66-1.03]) \text { or } \\
\text { alcohol rub (RR } \\
0.96,[0.76-1.20]) \\
\text { vs. control. }\end{array}$ \\
\hline $\begin{array}{l}\text { Luby et } \\
\text { al. }\end{array}$ & 2005 & $\begin{array}{l}\text { Cluster } \\
\text { RCT }\end{array}$ & 2 & $\begin{array}{l}\text { Symptoms of cough, } \\
\text { difficulty breathing, } \\
\text { congestion, or coryza }\end{array}$ & $\begin{array}{l}4,691 \text { partici- } \\
\text { pants and } 36 \\
\text { neighbour- } \\
\text { hoods }\end{array}$ & $\begin{array}{l}\text { 1. Plain soap } \\
\text { 2. Antibacte- } \\
\text { rial soap } \\
\text { 3. Standard } \\
\text { practice }\end{array}$ & $\begin{array}{l}\text { Symptoms in } \\
\text { all households } \\
\text { recorded. }\end{array}$ & $\begin{array}{l}\text { 1. Incidence } \\
\text { of } A R I \text { in } \\
\text { children }\end{array}$ & $\begin{array}{l}1.50 \% \text { reduction } \\
\text { with both soaps. } \\
2 . \text { Incidence } \\
\text { between } 2 \text { soaps } \\
\text { did not signifi- } \\
\text { cantly differ. }\end{array}$ \\
\hline $\begin{array}{l}\text { Larson } \\
\text { et al. }\end{array}$ & 2004 & $\begin{array}{l}\text { Dou- } \\
\text { ble- } \\
\text { blind } \\
\text { RCT }\end{array}$ & 2 & $\begin{array}{l}\text { Symptoms of fever, } \\
\text { sore throat, cough, } \\
\text { rhinorrhoea, con- } \\
\text { junctivitis }\end{array}$ & $\begin{array}{l}1,178 \text { subjects } \\
\text { in } 238 \text { house- } \\
\text { holds }\end{array}$ & $\begin{array}{l}\text { 1. Antibacte- } \\
\text { rial products } \\
\text { 2. Non- } \\
\text { antibacterial } \\
\text { products }\end{array}$ & $\begin{array}{l}\text { Symptoms in in- } \\
\text { dividual house- } \\
\text { hold members } \\
\text { assessed. }\end{array}$ & $\begin{array}{l}\text { 1. Risk for } \\
\text { symptoms } \\
\text { of ARI }\end{array}$ & $\begin{array}{l}\text { Risk not signifi- } \\
\text { cantly different } \\
\text { (RR } 0.96 \text { [0.82- } \\
1.12]) .\end{array}$ \\
\hline $\begin{array}{l}\text { Little et } \\
\text { al. }\end{array}$ & 2015 & $\mathrm{RCT}$ & 2 & $\begin{array}{l}\text { 1. RTIC } \\
\text { 2. ILId }\end{array}$ & $\begin{array}{l}20,066 \text { sub- } \\
\text { jects }\end{array}$ & $\begin{array}{l}\text { 1. Education } \\
\text { 2. No interven- } \\
\text { tion }\end{array}$ & $\begin{array}{l}\text { Nature and } \\
\text { frequency of } \\
\text { symptoms docu- } \\
\text { mented. }\end{array}$ & $\begin{array}{l}\text { 1. RTI/ILI } \\
\text { incidence }\end{array}$ & $\begin{array}{l}\text { Decreased risk of } \\
\text { RTI (RR } 0.86 \text { [0.83- } \\
0.89]) \text { and ILI (RR } \\
0.8 \text { [0.72-0.92]) vs. } \\
\text { control. }\end{array}$ \\
\hline $\begin{array}{l}\text { Carabin } \\
\text { et al. }\end{array}$ & 1999 & $\begin{array}{l}\text { Cluster } \\
\mathrm{RCT}\end{array}$ & 2 & $\begin{array}{l}\text { 1. Nasal discharge } \\
\text { + fever, sneezing, } \\
\text { cough, sore throat, } \\
\text { ear pain, malaise, or } \\
\text { irritability }\end{array}$ & $\begin{array}{l}1,729 \text { children } \\
\text { in } 47 \text { daycare } \\
\text { centres }\end{array}$ & $\begin{array}{l}\text { 1. Education } \\
\text { 2. No educa- } \\
\text { tion }\end{array}$ & $\begin{array}{l}\text { Absences and } \\
\text { daily occur- } \\
\text { rence of colds } \\
\text { recorded. }\end{array}$ & $\begin{array}{l}\text { 1. Incidence } \\
\text { of URI }\end{array}$ & $\begin{array}{l}\text { Intervention redu- } \\
\text { ced incidence of } \\
\text { URI (IRR } 0.80 \text { [0.68, } \\
0.93]) .\end{array}$ \\
\hline $\begin{array}{l}\text { Azor- } \\
\text { Marti- } \\
\text { nez et } \\
\text { al. }\end{array}$ & 2014 & $\mathrm{RCT}$ & 2 & 1. ILI $\left.\right|^{\mathrm{e}}$ & $\begin{array}{l}1,609 \text { children } \\
\text { in } 5 \text { schools }\end{array}$ & $\begin{array}{l}\text { 1. Soap, HS + } \\
\text { education } \\
\text { 2. Standard } \\
\text { practice }\end{array}$ & $\begin{array}{l}\text { Symptoms } \\
\text { collected for stu- } \\
\text { dent absences. }\end{array}$ & $\begin{array}{l}\text { 1. School } \\
\text { absentee- } \\
\text { ism due } \\
\text { to ILI }\end{array}$ & $\begin{array}{l}\text { Risk of absentee- } \\
\text { ism elevated with } \\
\text { no intervention } \\
\text { (RR 2.64 [2.16- } \\
3.21] \text { ). }\end{array}$ \\
\hline
\end{tabular}




\begin{tabular}{|c|c|c|c|c|c|c|c|c|c|}
\hline Study & Year & $\begin{array}{l}\text { Study } \\
\text { Design }\end{array}$ & LOE & Definition of VRTI & $\begin{array}{l}\text { No. of } \\
\text { Subjects }\end{array}$ & $\begin{array}{l}\text { Study } \\
\text { Group(s) }\end{array}$ & Study Protocol & $\begin{array}{l}\text { Primary } \\
\text { endpoint(s) }\end{array}$ & Conclusion \\
\hline $\begin{array}{l}\text { Roberts } \\
\text { et al. }\end{array}$ & 2000 & $\begin{array}{l}\text { Cluster } \\
\text { RCT }\end{array}$ & 2 & $\begin{array}{l}\text { Respiratory } \\
\text { symptoms }\end{array}$ & $\begin{array}{l}558 \text { children } \\
\text { in } 23 \text { childcare } \\
\text { centres }\end{array}$ & $\begin{array}{l}\text { 1. Education } \\
\text { 2. No educa- } \\
\text { tion }\end{array}$ & $\begin{array}{l}\text { Symptoms of } \\
\text { respiratory ill- } \\
\text { ness recorded. }\end{array}$ & $\begin{array}{l}\text { 1. Incidence } \\
\text { of colds per } \\
\text { child-year }\end{array}$ & $\begin{array}{l}\text { Reduction of colds } \\
\text { by } 17 \% \text { among } \\
\text { those } \leq 24 \text { months } \\
\text { of age. }\end{array}$ \\
\hline $\begin{array}{l}\text { Ban et } \\
\text { al. }\end{array}$ & 2015 & $\begin{array}{l}\text { Cluster } \\
\text { RCT }\end{array}$ & 2 & $\mathrm{ARI}^{f}$ & 466 children & $\begin{array}{l}\text { 1. Soap, } \\
\text { alcohol-based } \\
\text { HS } \\
\text { 2. Standard } \\
\text { practice }\end{array}$ & $\begin{array}{l}\text { Daily data on ill- } \\
\text { ness symptoms } \\
\text { collected. }\end{array}$ & 1. ARI illness & $\begin{array}{l}\text { Odds of } A R I \\
\text { reduced with } \\
\text { intervention (OR } \\
0.47[0.38-0.59])\end{array}$ \\
\hline $\begin{array}{l}\text { Correa } \\
\text { et al. }\end{array}$ & 2012 & $\begin{array}{l}\text { Cluster } \\
\text { RCT }\end{array}$ & 2 & $\left.A R\right|^{g}$ & $\begin{array}{l}1,727 \text { students } \\
\text { in } 42 \text { childcare } \\
\text { centres }\end{array}$ & $\begin{array}{l}\text { 1. Alcohol- } \\
\text { based HS } \\
\text { 2. Standard } \\
\text { practice }\end{array}$ & $\begin{array}{l}\text { ARI symptoms } \\
\text { recorded. }\end{array}$ & 1. ARI illness & $\begin{array}{l}\text { Significant risk } \\
\text { reduction with } \\
\text { intervention (HR } \\
0.69[0.57-0.83]) .\end{array}$ \\
\hline $\begin{array}{l}\text { Hubner } \\
\text { et al. }\end{array}$ & 2010 & $\mathrm{RCT}$ & 2 & $\begin{array}{l}\text { Common cold, sore } \\
\text { throat, fever, cough, } \\
\text { sinusitis, influenza }\end{array}$ & $\begin{array}{l}129 \text { employ- } \\
\text { ees }\end{array}$ & $\begin{array}{l}\text { 1. Alcohol- } \\
\text { based HS } \\
\text { 2. Standard } \\
\text { practice }\end{array}$ & $\begin{array}{l}\text { Respiratory } \\
\text { symptoms and } \\
\text { days of work } \\
\text { missed recorded. }\end{array}$ & $\begin{array}{l}\text { 1. Odds of } \\
\text { common } \\
\text { cold } \\
\text { 2. Days of } \\
\text { work missed }\end{array}$ & $\begin{array}{l}\text { HS reduced odds } \\
\text { (OR } 0.35 \text { [0.17- } \\
0.71]) \text { but not days } \\
\text { absent (OR } 0.50 \\
[0.22-1.17]) \text {. }\end{array}$ \\
\hline $\begin{array}{l}\text { Ram et } \\
\text { al. }\end{array}$ & 2015 & $\mathrm{RCT}$ & 2 & $\begin{array}{l}\text { 1. ILI } \\
\text { 2. Lab-confirmed } \\
\text { influenza }\end{array}$ & $\begin{array}{l}3,421 \text { partici- } \\
\text { pants within } \\
377 \text { house- } \\
\text { holds }\end{array}$ & $\begin{array}{l}\text { 1. Handwa- } \\
\text { shing } \\
\text { 2. Standard } \\
\text { practice }\end{array}$ & $\begin{array}{l}\text { Daily surveillan- } \\
\text { ce and collection } \\
\text { of oropharyn- } \\
\text { geal specimens } \\
\text { from contacts. }\end{array}$ & $\begin{array}{l}\text { 1. SAR } \\
\text { among } \\
\text { household } \\
\text { contacts }\end{array}$ & $\begin{array}{l}\text { No difference in } \\
\text { SARs for ILI (ratio } \\
1.24 \text { [0.92-1.65]) } \\
\text { or influenza (2.4 } \\
[0.68-8.47]) \text {. }\end{array}$ \\
\hline $\begin{array}{l}\text { Nichol- } \\
\text { son et } \\
\text { al. }\end{array}$ & 2014 & $\begin{array}{l}\text { Cluster } \\
\text { RCT }\end{array}$ & 2 & $A R I^{i}$ & $\begin{array}{l}11,725 \text { parti- } \\
\text { cipants within } \\
70 \text { neighbour- } \\
\text { hoods }\end{array}$ & $\begin{array}{l}\text { 1. Education + } \\
\text { plain bar soap } \\
\text { 2. Standard } \\
\text { practice }\end{array}$ & $\begin{array}{l}\text { Illnesses and } \\
\text { school absences } \\
\text { recorded. }\end{array}$ & $\begin{array}{l}\text { 1. ARI inci- } \\
\text { dence rate } \\
\text { 2. School } \\
\text { absentee- } \\
\text { ism }\end{array}$ & $\begin{array}{l}\text { Increased risk } \\
\text { of illness (by } \\
15 \% \text { ) and school } \\
\text { absence (by } 31 \% \text { ) } \\
\text { without soap use. }\end{array}$ \\
\hline $\begin{array}{l}\text { Slayton } \\
\text { et al. }\end{array}$ & 2016 & $\begin{array}{l}\text { Cluster } \\
\mathrm{RCT}\end{array}$ & 2 & $\begin{array}{l}\text { ARI (no definition } \\
\text { provided) }\end{array}$ & $\begin{array}{l}369 \text { partici- } \\
\text { pants within } \\
33 \text { geographi- } \\
\text { cal areas }\end{array}$ & $\begin{array}{l}\text { 1. Education + } \\
\text { antimicrobial } \\
\text { hand towels } \\
\text { 2. Education }\end{array}$ & $\begin{array}{l}\text { Information on } \\
\text { illness in the } \\
\text { past } 48 \text { hours } \\
\text { collected. }\end{array}$ & $\begin{array}{l}\text { 1. ARI illness } \\
\text { rate per } 100 \\
\text { person- } \\
\text { visits }\end{array}$ & $\begin{array}{l}\text { No significant dif- } \\
\text { ference between } \\
\text { intervention (1.38) } \\
\text { vs. control (1.48). }\end{array}$ \\
\hline $\begin{array}{l}\text { Shafi- } \\
\text { que et } \\
\text { al. }\end{array}$ & 2016 & $\begin{array}{l}\text { Cluster } \\
\text { RCT }\end{array}$ & 2 & URIj & $\begin{array}{l}227 \text { partici- } \\
\text { pants among } \\
48 \text { clusters }\end{array}$ & $\begin{array}{l}\text { 1. Benzalko- } \\
\text { nium chloride- } \\
\text { based HS } \\
\text { 2. Education }\end{array}$ & $\begin{array}{l}\text { URI symptoms } \\
\text { recorded daily. }\end{array}$ & $\begin{array}{l}\text { 1. Incidence } \\
\text { of URI }\end{array}$ & $\begin{array}{l}\text { No significant dif- } \\
\text { ference between } \\
\text { HS (30.2\%) and } \\
\text { control (34.4\%). }\end{array}$ \\
\hline $\begin{array}{l}\text { Morton } \\
\text { et al. }\end{array}$ & 2004 & $\begin{array}{l}\text { Cluster- } \\
\text { rando- } \\
\text { mized } \\
\text { study }\end{array}$ & 2 & $\begin{array}{l}\text { Symptoms of URI, } \\
\text { such as nasal con- } \\
\text { gestion, cough, or } \\
\text { sore throat, with or } \\
\text { without fever }\end{array}$ & 253 children & $\begin{array}{l}\text { 1. Alcohol gel } \\
+ \text { handwash- } \\
\text { ing } \\
\text { 2. Handwash- } \\
\text { ing }\end{array}$ & $\begin{array}{l}\text { Crossover study, } \\
\text { with 1-week } \\
\text { washout period. } \\
\text { Symptoms recor- } \\
\text { ded. }\end{array}$ & $\begin{array}{l}\text { 1. School } \\
\text { absentee- } \\
\text { ism for } \\
\text { respiratory } \\
\text { illness }\end{array}$ & $\begin{array}{l}\text { Alcohol gel } \\
\text { reduced odds of } \\
\text { absenteeism by } \\
43 \% \text {. }\end{array}$ \\
\hline
\end{tabular}

ARI: Acute respiratory illness, Cl: confidence interval, d: day, HR: hazard ratio, HS: hand sanitizer, ILI: influenza-like illness, IRR: incidence rate ratio, OR: odds ratio, RCT: randomized controlled trial, RTI: respiratory tract infection, SAR: secondary attack rate/ratio, URI: upper respiratory infection, VRTI: viral respiratory tract infection. ${ }^{a}<2$ years of age: Fever $>38^{\circ} \mathrm{C}$ and $\geq 1$ of the following: nasal discharge/congestion, cough, conjunctivitis, respiratory distress (tachypnea, retractions), sore throat, and new seizure; $>2$ years of age: fever $>38^{\circ} \mathrm{C}$ and cough or sore throat in the absence of another explanation. ${ }^{\mathrm{b}}$ At least two caregiver-reported symptoms for 1 day, or one of the following symptoms for 2 days (but not fever alone). ${ }^{\mathrm{C} T w o}$ of the following symptoms for 1 day or 1 of the following symptoms for 2 consecutive days, not including 2 consecutive days of cough alone, sneezing alone, or fever alone: runny nose, stuffy/blocked nose or noisy breathing, cough, feeling hot/feverish or having chills, sore throat, or sneezing. ${ }^{\mathrm{d}} \mathrm{High}$ temperature $\left(>37.5^{\circ} \mathrm{C}\right)$, a respiratory symptom, and a systemic symptom. ${ }^{e}(1)$ sudden appearance of symptoms; (2) at least 1 of the following 4 : fever/feeling feverish, body aches, headache, muscle aches, and (3) at least 1 of the following 3: cough, sore throat, difficulty breathing; and (4) absence of other suspected diagnosis. fSymptoms of fever $\left(>37.3^{\circ} \mathrm{C}\right)$, cough and expectoration, rhinorrhoea and nasal congestion. ${ }^{9} \geq 2$ of the following symptoms for $\geq 24$ hours, lasting $\geq 2$ days: runny, stuffy, or blocked nose or noisy breathing, cough, fever, hot sensation, or chills, and/or sore throat. Ear pain alone was considered ARI. ${ }^{\mathrm{h}}<5$ years old: fever; $\geq 5$ years old: fever with cough or sore throat. 'Pneumonia, cough, fever, chest pain and shortness of breath, cold,

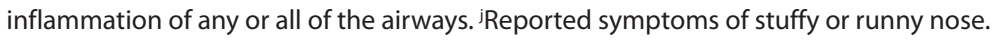


duction in VRTI-associated absenteeism, as high as $34.6 \%$, while the other did not ${ }^{(73)}$. Three other trials $s^{(74-76)}$ conducted in the community setting concurred that the effect of alcohol-based hand sanitizer use (combined with education) was weak. One study ${ }^{(71)}$ that examined the use of an alcohol-free hand sanitizer alone found a significant reduction in VRTI-associated absenteeism (31.7\%) in the intervention groups.

Two studies evaluating the effect of handwashing with soap compared with usual handwashing practices (control) provided conflicting findings. Hovi et al. ${ }^{(77)}$ found that while the use of soap and water significantly lowered the incidence of acute gastrointestinal infections (AGI) among office employees, that of respiratory tract infections was not, potentially due to different transmission routes. In contrast, Talaat et al. ${ }^{(70)}$ found significant reductions in both outcomes associated with AGI (33\%) and VRTI (40\%) in the intervention group. Of note, two studies ${ }^{(78,79)}$ that compared the effect of antibacterial soap versus non-antibacterial soap on respiratory illness rates in community settings both found no significant difference.

Of the two studies that examined education alone, both observed positive results, reporting either a significant decrease in risk ${ }^{(80)}$ or incidence ${ }^{(81)}$ of reported VRTI among those in the intervention arms. When all three hand hygiene interventions (i.e. hand sanitizer use, soap use, and education) were employed in the experimental group, two studies found a significant reduction in school absenteeism due to respiratory illness relative to the control group, which followed usual handwashing procedures $^{(82,83)}$.

In addition to schools, implementation of hand hygiene interventions was studied in other settings, including childcare centres, workplaces, and households. In one cluster RCT, Roberts et al. ${ }^{(84)}$ demonstrated high-quality evidence that the practice of hand hygiene in childcare centres significantly reduced the incidence of colds in children under 24 months of age and those who adhered best to the intervention. Two other trials provided evidence supporting its role in reducing VRTI incidence ${ }^{(85,86)}$. In a small individually randomized trial carried out in the workplace, Hubner et al. ${ }^{\left({ }^{(87)}\right.}$ reported that employees who used an alcohol- based hand gel had a significantly lower risk of a cold compared with control. In contrast, evidence of a protective effect when implemented in households is lacking. One study ${ }^{(88)}$ found no benefit of hand hygiene in reducing VRTI rates compared with education alone. To ascertain the effect of introducing hand hygiene interventions to prevent secondary household influenza transmission from an index case, three studies ${ }^{(89-91)}$ were executed. All found that the secondary attack rate did not significantly differ across the intervention arms. This observation may be explained by the relatively short study period in all three trials ( $\geq 21$ days), as participants require time to learn and adopt new hygiene behaviours before viral transmission can be interrupted. Furthermore, Sandora et al. ${ }^{(76)}$ reported that even when the intervention was implemented prior to any index case, no demonstrable benefit in preventing secondary household transmission of respiratory tract illnesses was seen.

Lastly, studies conducted in urban and rural domestic settings produced vastly different outcomes. Two trials ${ }^{(79,92)}$ performed in urban settlements provided high-quality evidence of reduced VRTIs in children after hand hygiene education and soap were introduced. Both studies promoted hand hygiene practices through regular group training sessions and household visits over a 10- to 12-month period. In contrast, two studies ${ }^{(93,94)}$ conducted in rural settings observed no such reduction with intervention.

\section{Summary: Hand hygiene}

1. Aggregate grade of evidence: $A$

2. Benefit: Decreased VRTI

3. Harm: Minimal: inconvenience, time, dry skin on hands

4. Cost: Low (costs of soap and hand sanitizers)

5. Benefits-harm assessment: Preponderance of benefit over harm

6. Value judgments: Low cost intervention with significant improvements in outcome of interest, gives high value for intervention

7. Recommendation level: Strong recommendation

8. Intervention: Employ hand hygiene strategies in healthcare and community settings.

Table 11. Summary of evidence for interventions to reduce VRTI transmission.

\begin{tabular}{|c|c|c|c|}
\hline Intervention & $\begin{array}{c}\text { Aggregate grade of } \\
\text { evidence }\end{array}$ & Balance of benefit to harm & Recommendation \\
\hline Nasal washing & C & Preponderance of benefit to harm & Option \\
\hline Gargling & C & Preponderance of benefit to harm & Option \\
\hline Masks (community settings) & B & Preponderance of benefit to harm & Recommendation \\
\hline Masks (healthcare settings) & A & Preponderance of benefit to harm & Strong recommendation \\
\hline $\begin{array}{l}\text { Other personal protective equipment } \\
\text { (gloves, gowns, eye protection) }\end{array}$ & C & Preponderance of benefit to harm & $\begin{array}{l}\text { Recommendation in healthcare } \\
\text { settings }\end{array}$ \\
\hline Social distancing & $\mathrm{N} / \mathrm{A}$ & $\mathrm{N} / \mathrm{A}$ & $\mathrm{N} / \mathrm{A}$ \\
\hline Hand hygiene & A & Preponderance of benefit to harm & Strong recommendation \\
\hline
\end{tabular}




\section{Discussion}

This review provides evidence-based recommendations of five broad nonpharmacological interventions (Table 11) aimed to reduce upper VRTI transmission amid an ongoing respiratory virus pandemic, with an impending cold and flu season in the Northern Hemisphere. With potential spread of disease through both air and physical contact, the nonpharmacological options assessed herein may be particularly meaningful in situations where efficacious antivirals and/or vaccines are in short supply or non-existent ${ }^{(2)}$.

Through the iterative process, mask use and hand hygiene have emerged as the most efficacious strategies to impede viral transmission. Their adoption in healthcare and community settings is supported by a high level of evidence, a favourable safety profile, and a preponderance of benefit over harm. However, as described in multiple included studies ${ }^{(57,61,84)}$, their effectiveness is contingent upon user compliance. This review was unable to determine the optimal mask type for use in either setting, which represents a study limitation. Nevertheless, based upon the available evidence, cloth masks should not be used in healthcare settings when surgical masks or $\mathrm{N} 95$ respirators are available. In addition, although the evidence supporting the use of gloves, gowns, and eye protection is weak, there is no data to suggest significant harm, beyond added cost and potential scarcity. Due to their potential benefit in high-risk situations, donning gloves, gowns, and eye protection are recommended in healthcare settings.

Saline nasal washing and gargling are two low-cost interventions with minimal potential harm. Although the available evidence suggests potential benefit for both, the limited available data suggest that these behavioural strategies are an option. Consideration of the potential risks of nasal washing and gargling, such as Eustachian tube dysfunction symptoms and throat irritation, should be considered. Individuals who are more susceptible to VRTIs and can tolerate nasal saline irrigation and/ or gargling may derive greater benefit from these interventions. Notably, in response to the COVID-19 pandemic, novel therapeutic and preventative strategies to combat SARS-CoV-2 are currently under investigation ${ }^{(95,96)}$. Further research is required to ascertain the optimal dosing for prophylaxis and the associated risks of these interventions.

Although a summary of findings for social distancing measures is not possible due to limited data from one study, some points are worth noting, particularly in the COVID-19 era. During the early stages of an outbreak or pandemic, the goal of social distancing is to reduce and delay the peak attack rate, thereby allowing time to accumulate resources, distribute antivirals, and administer vaccines if available ${ }^{(97)}$. In situations where antivirals and/or vaccines do not exist for a novel virus, such as the current predicament with SARS-CoV-2, these measures, which can be readily available and activated, may represent the first line of defence and play a more critical role in reducing the spread of the infectious virus.

This review is not intended to replace clinical judgment, but rather to aid clinicians, in particular rhinologists, in comprehending the available evidence and develop an evidence-based approach to identify efficacious, rapidly deployed NPIs to reduce viral transmission. Although the scope of this review is broad, we acknowledge that by limiting the inclusion criteria to studies with the highest level of evidence, emerging and anecdotal interventions with potentially meaningful clinical impact may have inadvertently been excluded. Furthermore, we chose to only examine studies that specified a clinical endpoint involving upper respiratory tract infections. Therefore, caution must be exercised when considering these recommendations in the context of preventing lower airway infections.

\section{Conclusion}

The five NPIs examined represent a small fraction of the armamentarium currently under investigation. The current pandemic has catalysed research efforts to reexamine existing methods and propose novel strategies to reduce viral exposure, such as modified protective equipment ${ }^{(98)}$ or topical nasal and oral applications of PVP-|(95). As the pandemic continues to unfold, these NPIs may serve as the only viable strategies to contain the outbreak until an efficacious vaccine is developed.

\section{Acknowledgement}

N/A

\section{Authorship contribution}

DAG, RJS, NRR: Concept and design; EY, JF, CS, EAB: Acquisition, analysis, or interpretation of data; EY, JF: Drafting of Manuscript; DAG, RJS, SAN, NRR: Critical revision of manuscript; DAG, RJS, SAN, NRR: Supervision.

\section{Conflict of interest}

RJS is a consultant for Stryker, Optinose, GSK, a medical director for Healthy Humming and has received grant support from Stryker, Optinose and Healthy Humming. NRR has received grant funding from Optinose US, Inc.

\section{Financial disclosure}

No funding has been received to support the development of this article. 


\section{References}

1. Fendrick AM, Monto AS, Nightengale B, Sarnes $M$. The economic burden of noninfluenza-related viral respiratory tract infection in the United States. Arch Intern Med. 2003;163(4):487-94.

2. Jefferson T, Del Mar CB, Dooley $L$, et al. Physical interventions to interrupt or reduce the spread of respiratory viruses. Cochrane Database Syst Rev. 2011;2011(7):Cd006207.

3. Singh S, Sharma N, Singh U, Singh T, Mangal DK, Singh V. Nasopharyngeal wash in preventing and treating upper respiratory tract infections: Could it prevent COVID-19? Lung India. 2020;37(3):246-51.

4. Rudmik L, Smith TL. Development of an evidence-based review with recommendations using an online iterative process. Int Forum Allergy Rhinol. 2011;1(6):431-7.

5. Rosenfeld RM, Shiffman RN. Clinical practice guidelines: a manual for developing evidence-based guidelines to facilitate performance measurement and quality improvement. Otolaryngol Head Neck Surg. 2006;135(4 Suppl):S1-28.

6. Shiffman RN, Shekelle P, Overhage JM, Slutsky J, Grimshaw J, Deshpande AM. Standardized reporting of clinical practice guidelines: a proposal from the Conference on Guideline Standardization. Ann Intern Med. 2003;139(6):493-8

7. Development and validation of an international appraisal instrument for assessing the quality of clinical practice guidelines: the AGREE project. Qual Saf Health Care 2003;12(1):18-23

8. Moher D, Altman DG, Liberati A, Tetzlaff J. PRISMA statement. Epidemiology. 2011;22(1):128; author reply

9. Oxford Centre for Evidence-Based Medicine. The Oxford Levels of Evidence 22016 [July 4, 2020]. Available from: https://www.cebm. net/2016/05/ocebm-levels-of-evidence/.

10. American Academy of Pediatrics Steering Committee on Quality Improvement and Management (AAP SC-QIM): Classifying Recommendations for Clinical Practice Guidelines. Pediatrics. 2004;114(3):874-7.

11. Barasheed O, Alfelali M, Mushta S, et al. Uptake and effectiveness of facemask against respiratory infections at mass gatherings: a systematic review. Int J Infect Dis. 2016:47:105-11

12. Ide K, Yamada H, Kawasaki Y. Effect of gargling with tea and ingredients of tea on the prevention of influenza infection: a metaanalysis. BMC Public Health. 2016;16:396.

13. Offeddu V, Yung CF, Low MSF, Tam CC. Effectiveness of Masks and Respirators Against Respiratory Infections in Healthcare Workers: A Systematic Review and MetaAnalysis. Clin Infect Dis. 2017;65(11):193442.

14. Rashid H, Ridda I, King C, et al. Evidence compendium and advice on social distancing and other related measures for response to an influenza pandemic. Paediatr Respir Rev. 2015;16(2):119-26.

15. Smith JD, MacDougall CC, Johnstone
J, Copes RA, Schwartz B, Garber GE. Effectiveness of N95 respirators versus surgical masks in protecting health care workers from acute respiratory infection: a systematic review and meta-analysis. Cmaj. 2016;188(8):567-74.

16. Aggarwal N, Dwarakanathan V, Gautam $N$, Ray A. Facemasks for prevention of viral respiratory infections in community settings: A systematic review and meta-analysis. Indian J Public Health. 2020;64(Supplement):S192-s200.

17. Bartoszko JJ, Farooqi MAM, Alhazzani W Loeb M. Medical masks vs N95 respirators for preventing COVID-19 in healthcare workers: A systematic review and metaanalysis of randomized trials. Influenza Other Respir Viruses. 2020;14(4):365-73.

18. Bin-Reza F, Lopez Chavarrias V, Nicoll A, Chamberland ME. The use of masks and respirators to prevent transmission of influenza: a systematic review of the scientific evidence. Influenza Other Respir Viruses. 2012;6(4):257-67.

19. Chou R, Dana T, Jungbauer R, Weeks C McDonagh MS. Masks for Prevention of Respiratory Virus Infections, Including SARS-CoV-2, in Health Care and Community Settings: A Living Rapid Review. Ann Intern Med. 2020

20. Cowling BJ, Zhou Y, Ip DK, Leung GM Aiello AE. Face masks to prevent transmission of influenza virus: a systematic review. Epidemiol Infect. 2010;138(4):449-56.

21. Iannone $P$, Castellini $G$, Coclite $D$, et al. The need of health policy perspective to protect Healthcare Workers during COVID-19 pandemic. A GRADE rapid review on the N95 respirators effectiveness. PLoS One. 2020;15(6):e0234025.

22. Liang W, Guan W, Chen R, et al. Cancer patients in SARS-CoV-2 infection: a nationwide analysis in China. Lancet Oncol. 2020;21(3):335-7.

23. Long $Y, H u T$, Liu L, et al. Effectiveness of N95 respirators versus surgical masks against influenza: A systematic review and metaanalysis. J Evid Based Med. 2020;13(2):93101.

24. Maclntyre CR, Chughtai AA. A rapid systematic review of the efficacy of face masks and respirators against coronaviruses and other respiratory transmissible viruses for the community, healthcare workers and sick patients. Int J Nurs Stud. 2020;108:103629.

25. McGuinness SL, Barker SF, O'Toole J, et al. Effect of hygiene interventions on acute respiratory infections in childcare, school and domestic settings in low- and middleincome countries: a systematic review. Trop Med Int Health. 2018;23(8):816-33

26. Moncion K, Young K, Tunis M, Rempel S Stirling R, Zhao L. Effectiveness of hand hygiene practices in preventing influenza virus infection in the community setting: A systematic review. Can Commun Dis Rep. 2019;45(1):12-23.

27. Rabie T, Curtis V. Handwashing and risk of respiratory infections: a quantitative sys- tematic review. Trop Med Int Health. 2006;11(3):258-67

28. Serra ME. Prevention of respiratory infections at day care centers: recommendations and systematic review of the evidence. Arch Argent Pediatr. 2014;112(4):323-31.

29. Wang Z, Lapinski M, Quilliam E, Jaykus LA, Fraser $A$. The effect of hand-hygiene interventions on infectious disease-associated absenteeism in elementary schools: A systematic literature review. Am J Infect Control. 2017;45(6):682-9.

30. Warren-Gash C, Fragaszy E, Hayward AC. Hand hygiene to reduce community transmission of influenza and acute respiratory tract infection: a systematic review. Influenza Other Respir Viruses. 2013;7(5):738-49.

31. Wong VW, Cowling BJ, Aiello AE. Hand hygiene and risk of influenza virus infections in the community: a systematic review and meta-analysis. Epidemiol Infect. 2014;142(5):922-32.

32. Aiello AE, Coulborn RM, Perez V, Larson EL. Effect of hand hygiene on infectious disease risk in the community setting: a meta-analysis. Am J Public Health. 2008;98(8):1372-81.

33. Gera T, Shah D, Sachdev HS. Impact of Water, Sanitation and Hygiene Interventions on Growth, Non-diarrheal Morbidity and Mortality in Children Residing in Low- and Middle-income Countries: A Systematic Review. Indian Pediatr. 2018:55(5):381-93.

34. Lam W, Dawson A, Fowler C. Health promotion interventions to prevent early childhood human influenza at the household level: a realist review to identify implications for programmes in Hong Kong. J Clin Nurs. 2015:24(7-8):891-905.

35. Mbakaya BC, Lee PH, Lee RL. Hand Hygiene Intervention Strategies to Reduce Diarrhoea and Respiratory Infections among Schoolchildren in Developing Countries: A Systematic Review. Int J Environ Res Public Health. 2017;14(4).

36. Saunders-Hastings P, Crispo JAG, Sikora L, Krewski D. Effectiveness of personal protective measures in reducing pandemic influenza transmission: A systematic review and meta-analysis. Epidemics. 2017;20:1-20.

37. Willmott $M$, Nicholson A, Busse $H_{\text {, }}$ MacArthur GJ, Brookes S, Campbell R. Effectiveness of hand hygiene interventions in reducing illness absence among children in educational settings: a systematic review and meta-analysis. Arch Dis Child. 2016;101(1):42-50

38. Xiao J, Shiu EYC, Gao H, et al. Nonpharmaceutical Measures for Pandemic Influenza in Nonhealthcare SettingsPersonal Protective and Environmental Measures. Emerg Infect Dis. 2020;26(5):96775.

39. Zivich PN, Gancz AS, Aiello AE. Effect of hand hygiene on infectious diseases in the office workplace: A systematic review. Am J Infect Control. 2018;46(4):448-55.

40. Smith SM, Sonego S, Wallen GR, Waterer G, Cheng AC, Thompson P. Use of non- 
pharmaceutical interventions to reduce the transmission of influenza in adults: A systematic review. Respirology. 2015;20(6):896903.

41. Chen $W Q$, Ling $W H$, Lu CY, et al. Which preventive measures might protect health care workers from SARS? BMC Public Health 2009;9:81.

42. Liu W, Tang F, Fang L-Q, et al. Risk factors for SARS infection among hospital healthcare workers in Beijing: a case control study. Trop Med Int Health. 2009;14(s1):52-9.

43. Nishiura H, Kuratsuji T, Quy T, et al. Rapid awareness and transmission of severe acute respiratory syndrome in Hanoi French Hospital, Vietnam. Am J Trop Med Hyg. 2005;73(1):17-25.

44. Seto WH, Tsang D, Yung RW, et al. Effectiveness of precautions against droplets and contact in prevention of nosocomial transmission of severe acute respiratory syndrome (SARS). Lancet. 2003:361(9368):1519-20.

45. Teleman MD, Boudville IC, Heng BH, Zhu D, Leo YS. Factors associated with transmis sion of severe acute respiratory syndrome among health-care workers in Singapore. Epidemiol Infect. 2004;132(5):797-803.

46. Yin WW, Gao LD, Lin WS, et al. [Effectiveness of personal protective measures in prevention of nosocomial transmission of severe acute respiratory syndrome]. Zhonghua Liu Xing Bing Xue Za Zhi. 2004;25(1):18-22.

47. Ide K, Yamada H, Matsushita K, et al. Effects of green tea gargling on the prevention of influenza infection in high school students: a randomized controlled study. PLoS One. 2014;9(5):e96373

48. Satomura K, Kitamura T, Kawamura T, et al. Prevention of upper respiratory tract infections by gargling: a randomized trial. Am J Prev Med. 2005;29(4):302-7

49. Toyoizumi K, Yamada H, Matsumoto K Sameshima Y. Gargling with Green Tea for Influenza Prophylaxis: A Pilot Clinical Study. Jpn J Clin Pharmacol Ther. 2013;44(6):45961.

50. Yamada H, Daimon T, Matsuda K, Yoshida M, Takuma N, Hara Y. A Randomized Controlled Study on the Effects of Gargling with Tea Catechin Extracts on the Prevention of Influenza Infection in Healthy Adults. Rinsho yakuri/Japanese J Clin Pharmacol Therap. 2007;38(5):323-30.

51. Miyaki K, Sakurazawa H, Mikurube H, et al An effective quarantine measure reduced the total incidence of influenza A H1N1 in the workplace: another way to control the H1N1 flu pandemic. J Occup Health. 2011:53(4):287-92.

52. Aiello AE, Murray GF, Perez $V$, et al. Mask use, hand hygiene, and seasonal influenza-like illness among young adults: a randomized intervention trial. J Infect Dis. 2010;201(4):491-8.

53. Aiello $A E$, Perez V, Coulborn RM, Davis BM Uddin M, Monto AS. Facemasks, hand hygiene, and influenza among young adults: a randomized intervention trial. PLoS One. 2012;7(1):e29744.

54. Barasheed O, Almasri N, Badahdah AM, et al. Pilot Randomised Controlled Trial to Test Effectiveness of Facemasks in Preventing Influenza-like IIIness Transmission among Australian Hajj Pilgrims in 2011. Infect Disord Drug Targets. 2014;14(2):110-6.

55. Canini L, Andréoletti L, Ferrari $P$, et al. Surgical mask to prevent influenza transmission in households: a cluster randomized trial. PLoS One. 2010;5(11):e13998.

56. Cowling BJ, Fung RO, Cheng CK, et al. Preliminary findings of a randomized trial of non-pharmaceutical interventions to prevent influenza transmission in households. PLoS One. 2008;3(5):e2101.

57. Maclntyre CR, Cauchemez S, Dwyer DE, et al. Face mask use and control of respiratory virus transmission in households. Emerg Infect Dis. 2009;15(2):233-41.

58. aclntyre CR, Zhang $Y$, Chughtai AA, et al. Cluster randomised controlled trial to examine medical mask use as source control for people with respiratory illness. BMJ Open. 2016;6(12):e012330.

59. Suess T, Remschmidt C, Schink SB, et al. The role of facemasks and hand hygiene in the prevention of influenza transmission in households: results from a cluster randomised trial; Berlin, Germany, 2009-2011. BMC Infect Dis. 2012;12:26.

60. Maclntyre CR, Wang $Q$, Seale $H$, et al. A randomized clinical trial of three options for $\mathrm{N} 95$ respirators and medical masks in health workers. Am J Respir Crit Care Med. 2013;187(9):960-6.

61. Maclntyre CR, Wang Q, Cauchemez S, et al. A cluster randomized clinical trial comparing fit-tested and non-fit-tested N95 respirators to medical masks to prevent respiratory virus infection in health care workers. Influenza Other Respir Viruses. 2011:5(3):170-9.

62. Maclntyre CR, Seale H, Dung TC, et al. A cluster randomised trial of cloth masks compared with medical masks in healthcare workers. BMJ Open. 2015;5(4):e006577.

63. Jacobs JL, Ohde S, Takahashi O, Tokuda Y, Omata F, Fukui T. Use of surgical face masks to reduce the incidence of the common cold among health care workers in Japan: a randomized controlled trial. Am J Infect Control. 2009:37(5):417-9.

64. Loeb M, Dafoe N, Mahony J, et al. Surgical mask vs N95 respirator for preventing influenza among health care workers: a randomized trial. Jama. 2009;302(17):1865-71.

65. Radonovich LJ, Jr., Simberkoff MS, Bessesen MT, et al. N95 Respirators vs Medical Masks for Preventing Influenza Among Health Care Personnel: A Randomized Clinical Trial. Jama. 2019;322(9):824-33.

66. Bowen $\mathrm{A}, \mathrm{Ma} \mathrm{H}, \mathrm{Ou}$ J, et al. A cluster-randomized controlled trial evaluating the effect of a handwashing-promotion program in Chinese primary schools. Am J Trop Med Hyg. 2007;76(6):1166-73.
67. Pandejpong D, Danchaivijitr S, Vanprapa N, Pandejpong T, Cook EF. Appropriate timeinterval application of alcohol hand gel on reducing influenza-like illness among preschool children: a randomized, controlled trial. Am J Infect Control. 2012;40(6):507-11.

68. Pickering AJ, Davis J, Blum AG, et al. Access to waterless hand sanitizer improves student hand hygiene behavior in primary schools in Nairobi, Kenya. Am J Trop Med Hyg. 2013;89(3):411-8.

69. Patel MK, Harris JR, Juliao P, et al. Impact of a hygiene curriculum and the installation of simple handwashing and drinking water stations in rural Kenyan primary schools on student health and hygiene practices. Am J Trop Med Hyg. 2012;87(4):594-601.

70. Talaat M, Afifi S, Dueger E, et al. Effects of hand hygiene campaigns on incidence of laboratory-confirmed influenza and absenteeism in schoolchildren, Cairo, Egypt. Emerg Infect Dis. 2011;17(4):619-25.

71. White CG, Shinder FS, Shinder AL, Dyer DL. Reduction of illness absenteeism in elementary schools using an alcoholfree instant hand sanitizer. J Sch Nurs. 2001;17(5):258-65.

72. Priest P, McKenzie JE, Audas R, Poore M, Brunton C, Reeves L. Hand sanitiser provision for reducing illness absences in primary school children: a cluster randomised trial. PLoS Med. 2014;11(8):e1001700.

73. Sandora TJ, Shih MC, Goldmann DA Reducing absenteeism from gastrointestinal and respiratory illness in elementary school students: a randomized, controlled trial of an infection-control intervention. Pediatrics. 2008;121(6):e1555-62.

74. Stebbins S, Cummings DA, Stark JH, et al. Reduction in the incidence of influenza A but not influenza B associated with use of hand sanitizer and cough hygiene in schools: a randomized controlled trial. Pediatr Infect Dis J. 2011;30(11):921-6.

75. Kotch JB, Weigle KA, Weber DJ, et al. Evaluation of an hygienic intervention in child day-care centers. Pediatrics. 1994;94(6 Pt 2):991-4.

76. Sandora TJ, Taveras EM, Shih MC, et al. A randomized, controlled trial of a multifaceted intervention including alcohol-based hand sanitizer and hand-hygiene education to reduce illness transmission in the home. Pediatrics. 2005;116(3):587-94.

77. Hovi T, Ollgren J, Savolainen-Kopra C. Intensified hand-hygiene campaign including soap-and-water wash may prevent acute infections in office workers, as shown by a recognized-exposure -adjusted analysis of a randomized trial. BMC Infect Dis. 2017;17(1):47.

78. Larson EL, Lin SX, Gomez-Pichardo C, Della-Latta P. Effect of antibacterial home cleaning and handwashing products on infectious disease symptoms: a randomized, double-blind trial. Ann Intern Med. 2004;140(5):321-9.

79. Luby SP, Agboatwalla M, Feikin DR, et al. 
Effect of handwashing on child health: a randomised controlled trial. Lancet. 2005;366(9481):225-33.

80. Little P, Stuart B, Hobbs FD, et al. An internet-delivered handwashing intervention to modify influenza-like illness and respiratory infection transmission (PRIMIT): a primary care randomised trial. Lancet. 2015;386(10004):1631-9.

81. Carabin H, Gyorkos TW, Soto JC, Joseph L, Payment P, Collet JP. Effectiveness of a training program in reducing infections in toddlers attending day care centers. Epidemiology. 1999;10(3):219-27

82. Azor-Martínez E, Gonzalez-Jimenez Y, SeijasVazquez ML, et al. The impact of common infections on school absenteeism during an academic year. Am J Infect Control. 2014;42(6):632-7.

83. Morton JL, Schultz AA. Healthy Hands: Use of alcohol gel as an adjunct to handwashing in elementary school children. J Sch Nurs. 2004;20(3):161-7.

84. Roberts L, Smith W, Jorm L, Patel M Douglas RM, McGilchrist C. Effect of infection control measures on the frequency of upper respiratory infection in child care: a randomized, controlled trial. Pediatrics. 2000;105(4 Pt 1):738-42.

85. Ban HQ, Li T, Shen J, et al. Effects of Multiple Cleaning and Disinfection Interventions on Infectious Diseases in Children: A Group Randomized Trial in China. Biomed Environ Sci. 2015;28(11):779-87

86. Correa JC, Pinto D, Salas LA, Camacho JC, Rondón M, Quintero J. A cluster-randomized controlled trial of handrubs for prevention of infectious diseases among children in Colombia. Rev Panam Salud Publica. 2012;31(6):476-84.

87. Hübner NO, Hübner C, Wodny M, Kampf G Kramer A. Effectiveness of alcohol-based hand disinfectants in a public administration: impact on health and work performance related to acute respiratory symptoms and diarrhoea. BMC Infect Dis. 2010;10:250.
88. Larson EL, Ferng YH, Wong-McLoughlin J, Wang S, Haber M, Morse SS. Impact of nonpharmaceutical interventions on URIs and influenza in crowded, urban households. Public Health Rep. 2010;125(2):178-91.

89. Cowling BJ, Chan KH, Fang VJ, et al. Facemasks and hand hygiene to prevent influenza transmission in households: a cluster randomized trial. Ann Intern Med. 2009:151(7):437-46

90. Ram PK, DiVita MA, Khatun-e-Jannat K et al. Impact of Intensive Handwashing Promotion on Secondary Household Influenza-Like IIIness in Rural Bangladesh: Findings from a Randomized Controlled Trial. PLoS One. 2015;10(6):e0125200.

91. Simmerman JM, Suntarattiwong P, Levy J, et al. Findings from a household randomized controlled trial of hand washing and face masks to reduce influenza transmission in Bangkok, Thailand. Influenza Other Respir Viruses. 2011;5(4):256-67.

92. Nicholson JA, Naeeni M, Hoptroff $M$, et al. An investigation of the effects of a hand washing intervention on health outcomes and school absence using a randomised trial in Indian urban communities. Trop Med Int Health. 2014;19(3):284

93. Shafique S, Sellen DW, Lou W, Jalal CS Jolly SP, Zlotkin SH. Mineral- and vitaminenhanced micronutrient powder reduces stunting in full-term low-birth-weight infants receiving nutrition, health, and hygiene education: a $2 \times 2$ factorial, clusterrandomized trial in Bangladesh. Am J Clin Nutr. 2016;103(5):1357-69

94. Slayton RB, Murphy JL, Morris J, et al. A Cluster Randomized Controlled Evaluation of the Health Impact of a Novel Antimicrobial Hand Towel on the Health of Children Under 2 Years Old in Rural Communities in Nyanza Province, Kenya. Am J Trop Med Hyg. 2016;94(2):437-44.

95. Mady LJ, Kubik MW, Baddour K, Snyderman $\mathrm{CH}$, Rowan NR. Consideration of povidoneiodine as a public health intervention for COVID-19: Utilization as "Personal Protective
Equipment" for frontline providers exposed in high-risk head and neck and skull base oncology care. Oral Oncol. 2020;105:104724.

96. Meyers C, Robison R, Milici J, et al. Lowering the transmission and spread of human coronavirus. J Med Virol. 2020 Sep 17. doi: 10.1002/jmv.26514.

97. Kelso JK, Milne GJ, Kelly H. Simulation suggests that rapid activation of social distancing can arrest epidemic development due to a novel strain of influenza. BMC Public Health. 2009;9(1):117.

98. Workman AD, Welling DB, Carter BS, et al. Endonasal instrumentation and aerosolization risk in the era of COVID-19: simulation, literature review, and proposed mitigation strategies. Int For Allergy Rhinol. 2020;10(7):798-805.

Nicholas R. Rowan, MD

Johns Hopkins

Department of Otolaryngology-

Head and Neck Surgery

601 N. Caroline St, 6th floor, Ste 6230

Baltimore

MD 21287

USA

Tel: +1-410-955-2307

Fax: +1-410-955-0035

E-mail: nrowan1@jhmi.edu
Appendix 1. Detailed search strategy.

PubMed (U.S. National Library of Medicine, National Institutes of Health) search strategy:

("Respiratory Tract Infections"[Majr] OR respiratory[ti] OR "respiratory tract infections" $[\mathrm{tw}] \mathrm{OR}$ "respiratory infections" [tw] OR "respiratory virus" [tw] OR "respiratory viruses" [tw] OR "respiratory illnesses"[tw] OR "respiratory disease"[tw] OR URI[tiab] OR VURI[tiab] OR "influenza transmission" [tw] OR "Common Cold"[Mesh] OR "common cold"[tw] OR "Influenza, Human"[Mesh] OR influenza[tw] OR

\section{APPENDIX}

"Laryngitis"[Mesh] OR laryngitis[tw] OR "Croup"[Mesh] OR croup[tw] OR laryngotracheitis[tw] OR "Pharyngitis"[Mesh] OR pharyngitis[tw] OR "Nasopharyngitis"[Mesh] OR nasopharyngitis[tw] OR "Rhinitis"[Mesh] OR rhinitis[tw] OR "Severe Acute Respiratory Syndrome"[Mesh] OR "Severe Acute Respiratory Syndrome"[tw] OR SARS[ti] OR "Sinusitis"[Mesh] OR sinusitis[tw] OR "Supraglottitis"[Mesh] OR supraglottitis[tw] OR "Epiglottitis"[Mesh] OR epiglottitis[tw] OR "Tracheitis"[Mesh] OR tracheitis[tw] OR "Middle East Respiratory Syndrome Coronavirus"[Mesh] OR "Middle East Respiratory Syndrome"[tw] OR MERS[ti] OR "Coronavirus"[Mesh] OR "Coronavirus Infections"[Mesh] OR coronavirus*[tw] OR 
COVID-19[tw] OR "Otitis Media"[Mesh] OR otitis media[tw] OR mastoiditis[tw] OR petrositis[tw]) AND ("Hand Hygiene"[Mesh] OR "hand hygiene"[tw] OR "Hand Disinfection"[Mesh] OR "hand disinfection" [tw] OR "hand disinfectants" [tw] OR handwashing[tw] OR "hand washing" [tw] OR "hand sanitation"[tw] OR "Hand Sanitizers"[Mesh] OR "hand sanitizer" [tw] OR "hand cleaners" [tw] OR gargling[tw] OR gargle[ti] OR "saline gargles"[tw] OR "Nasal Lavage"[Mesh] OR "nasal irrigation" [tw] OR "nasal wash"[tw] OR "nasal washing" [tw] OR "nasal rinse" [tw] OR "nasal rinsing" [tw] OR "nasopharyngeal wash"[tw] OR "Mouthwashes"[Mesh] OR mouthwash*[tw] OR mouthrinse[tw] OR "social distancing"[tw] OR "physical distancing" [tw] OR distancing[ti] OR "Social Isolation"[Mesh] OR isolation[tw] OR "Quarantine"[Mesh] OR quarantin*[tw] OR "mass gatherings"[tw] OR "physical interventions" [tw] OR "Personal Protective Equipment"[Mesh] OR "personal protective equipment" [tw] OR PPE[ti] OR "Surgical Attire"[Mesh] OR "personal protection"[tw] OR "protective materials"[tw] OR "protective measures"[tw] OR masks[tw] OR facemasks[tw] OR N95[tw] OR "Respiratory Protective Devices"[Mesh] OR "respiratory protective devices"[tw] OR "respirator protection"[tw] OR gloves[tw]) AND ("Respiratory Tract Infections/prevention and control"[Mesh] OR "prevention and control"[Subheading] OR prevent*[ti] OR "Respiratory Tract Infections/transmission"[Mesh] OR "transmission"[Subheading] OR transmission[ti] OR prophylaxis[tw] OR interrupt[ti] OR "Risk Reduction Behavior"[Mesh] OR "risk reduction"[tw] OR "risk mitigation"[tw] OR risk[ti]) AND ("Systematic Review"[Publication Type] OR "Systematic Reviews as Topic"[Mesh] OR systematic[sb] OR systematic review[tw] OR "Meta-Analysis"[Publication Type] OR "Meta-Analysis as Topic"[Mesh] OR "Network MetaAnalysis"[Mesh] OR meta-analy*[tw] OR metaanaly*[tw] OR quantitative review[tiab] OR quantitative overview[tiab] OR quantitative synthes*[tiab] OR critical analysis[tw] OR pooled analy*[tiab] OR meta-regression*[tiab] OR metaregression*[tiab] OR data synthes* ${ }^{*}$ tiab] OR data extraction[tiab] OR data abstraction*[tiab] OR "rapid review") NOT ("Animals"[Mesh] NOT "Humans"[Mesh])

- Number of records identified: 210

Scopus (Elsevier) search strategy:

((TITLE(respiratory OR SARS OR MERS) OR TITLE-ABS-

KEY("respiratory tract" OR "respiratory infections" OR "respiratory virus" OR "respiratory viruses" OR "respiratory illnesses" OR "respiratory disease" OR URI OR VURI OR "common cold" OR influenza OR laryngitis OR croup OR laryngotracheitis OR pharyngitis)OR TITLE-ABS-KEY(nasopharyngitis OR rhinitis OR "Severe Acute Respiratory Syndrome" OR sinusitis OR supraglottitis OR epiglottitis OR tracheitis OR "Middle East Respiratory Syndrome" OR coronavirus* OR COVID-19 OR "otitis media" OR mastoiditis
OR petrositis))) AND ((TITLE-ABS-KEY("hand hygiene" OR "hand disinfection" OR "hand disinfectants" OR handwashing OR "hand washing" OR "washing hands" OR "hand sanitation" OR "hand sanitizer" OR "hand sanitizers" OR "hand cleaners" OR gargling OR gargle* ) OR TITLE-ABS-KEY("nasal lavage" OR "nasal irrigation" OR "nasal wash" OR "nasal washing" OR "nasal rinse" OR "nasal rinsing" OR "nasopharyngeal wash" OR mouthwash* OR mouthrinse OR "social distancing" OR "physical distancing" OR isolation OR quarantine )OR TITLE-ABS-KEY("mass gatherings" OR "physical interventions" OR "personal protective" OR PPE[ti] $O R$ "surgical attire" OR "personal protection" OR "protective materials" OR masks OR facemasks OR N95 OR "respiratory protective devices" OR "respirator protection" OR gloves))) AND (TITLEABS-KEY(prevent* OR prophylaxis OR risk OR transmission)) AND ((TITLE(systematic) OR TITLE-ABS-KEY("systematic review" OR meta-analy* OR metaanaly* OR "quantitative review" OR "quantitative overview" OR "quantitative synthesis" OR "critical analysis" )OR TITLE-ABS-KEY("pooled analysis" OR "meta-regression" OR metaregression OR "data synthesis" OR "data extraction" OR "data abstraction" OR "rapid review")))

- Number of records identified: 373

CINAHL (EBSCOhost) search strategy:

(MH "Respiratory Tract Infections" OR respiratory OR URI OR VURI OR MH "Common Cold" OR MH "Influenza+" OR MH "Laryngitis+" OR MH "Croup" OR laryngotracheitis OR MH "Pharyngitis" OR nasopharyngitis OR MH "Rhinitis+" OR MH "Severe Acute Respiratory Syndrome" OR SARS OR MH "Sinusitis+" OR supraglottitis OR MH "Epiglottitis" OR tracheitis OR MH "Middle East Respiratory Syndrome Coronavirus") OR (MH "Middle East Respiratory Syndrome" OR MERS OR MH "Coronavirus+" OR MH "Coronavirus Infections+" OR COVID-19 OR MH "Otitis Media+" OR MH "Mastoiditis" OR petrositis) AND (MH "Handwashing+" OR gargl* OR MH "Nasal Lavage" OR MH "Mouthwashes+" OR "social distancing" OR "physical distancing" OR MH "Social Isolation+" OR MH "Quarantine" OR "personal protective" OR MH "Protective Clothing+" OR MH "Masks" OR facemasks OR N95 OR MH "Respiratory Protective Devices" OR "respirator protection" OR MH "Gloves") AND (prevent* OR MH "Respiratory Tract Infections+/ $P C$ " OR MW "PC" OR risk OR transmission)

- Number of records identified: 51

- Limiters: Publication Types: Meta-Analysis, Meta Synthesis, Systematic Review

- $\quad$ Expanders: Apply equivalent subjects

- Search modes: Boolean/Phrase

- Note: The search strategy below has to be pasted one line at a time (one concept on each line). If the entire search strategy is pasted onto the top row of the search box, the results will not be accurate. 